\title{
Vapor Phase Deoxygenation of Heptanoic Acid over Silica-Supported
}

\section{Palladium and Palladium-Tin Catalysts}

Nicholas Kaylor ${ }^{1}$, Jiahan Xie ${ }^{1}$, Yong-Su Kim ${ }^{2}$, Hien Pham ${ }^{3}$, Abhaya K. Datye, ${ }^{3}$ Yong-Kul Lee ${ }^{2}$, Robert J. Davis $^{1 *}$

${ }^{1}$ Department of Chemical Engineering, University of Virginia, Charlottesville, VA 22904-4741, United States

${ }^{2}$ Department of Chemical Engineering, Dankook University, 152 Jukjeonro, Yongin 16890, South Korea

${ }^{3}$ Department of Chemical and Biological Engineering and Center for Microengineered Materials, University of New Mexico, Albuquerque, NM 87131, United States

*Author to whom correspondence is addressed

Postage: 102 Engineers' Way, PO Box 400741, Charlottesville, VA 22904-4741, United States

Phone: 1-434-924-6284

Email: rjd4f@virginia.edu 


\begin{abstract}
Silica-supported Pd and PdSn catalysts were prepared by ion exchange or incipient wetness impregnation and characterized with $\mathrm{H}_{2}$ chemisorption, X-ray diffraction, in situ Sn K-edge X-ray absorption near edge structure (XANES), and transmission electron microscopy. The activity of the catalysts was evaluated in the deoxygenation of vapor-phase heptanoic acid at $0.1 \mathrm{MPa}$ and $573 \mathrm{~K} . \mathrm{A} \mathrm{Pd}$ catalyst synthesized via ion exchange formed nanoparticles of $1.1 \pm 0.4 \mathrm{~nm}$ and was more stable in heptanoic acid conversion compared to a Pd catalyst synthesized via incipient wetness impregnation having nanoparticles of $2.4 \pm 0.5 \mathrm{~nm}$. The addition of Sn to a Pd catalyst by either co-impregnation of precursors or physical mixing of supported monometallic catalysts improved the overall catalyst stability. Moreover, Sn addition expanded the reaction network from primarily decarbonylation over Pd to include dehydration and decarboxylative ketonization over PdSn. Electron microscopy confirmed the physical migration of Sn during catalytic reaction. In situ XANES analysis during the deoxygenation of a carboxylic acid suggests that partially reduced $\mathrm{SnO}_{x}$ is the active $\mathrm{Sn}$ phase associated with $\mathrm{Pd}$ nanoparticles under reaction conditions.
\end{abstract}

Key words: Pd; Sn; bimetallic heterogeneous catalysts; physical mixture; deoxygenation; carboxylic acids; migration 


\section{Introduction}

Biomass is a promising alternative feedstock to petroleum and other fossil carbon sources that is both renewable and readily available. ${ }^{1-3}$ Biomass-derived molecules often contain a significantly higher oxygen content compared to molecules obtained from fossil resources. Therefore, oxygen must be selectively removed from those biomass-derived compounds to produce chemicals and fuels. This can be accomplished via several classes of chemical reactions including decarbonylation, decarboxylation, decarboxylative ketonization, and dehydration. ${ }^{4-7}$

Interest in the deoxygenation of biomass-derived organic acids has increased because of a higher demand for biodiesel. ${ }^{8}$ Hydrocarbons can be produced via decarboxylation and decarbonylation of carboxylic acids. Snåre et al. investigated a wide variety of metal catalysts for the transformations, utilizing stearic acid as the model carboxylic acid to produce the diesel-like molecule $\mathrm{n}$-heptadecane at $573 \mathrm{~K}^{4}$ Continuous flow experiments revealed that $\mathrm{Pd} / \mathrm{C}$ and $\mathrm{Pt} / \mathrm{C}$ catalysts deactivate rapidly during deoxygenation reactions utilizing lauric acid as the model acid, ${ }^{9}$ depending on the concentration of carboxylic acid in the feed. Faster deactivation occurred when greater concentrations of lauric acid contacted the catalyst. The specific cause of catalyst deactivation, however, is not clear. Mäki-Arvela et al. concluded that coking occurs ${ }^{9}$ while others indicate that the carbonaceous species on the catalyst surface are not associated with traditional coke. ${ }^{10,11}$ Ping et al. reported that the decrease in the rate of decarbonylation of stearic acid over $\mathrm{Pd} / \mathrm{SiO}_{2}$ results from the adsorption of stearic acid on active sites together with adsorption of unsaturated products and $\mathrm{CO}^{10}$

Sun et al. recently demonstrated how the stability of Pd catalysts used in deoxygenation reactions in $10 \% \mathrm{H}_{2} / \mathrm{He}$ at $533 \mathrm{~K}$ depends on the Pd particle size and alloying. ${ }^{11}$ Larger Pd particles were more stable for the deoxygenation of octanoic acid and alloying Pd with Au further improved the stability of the catalyst. 
Recent work by Lopez-Ruiz et al. targeted high value alpha olefins formed by the decarbonylation of concentrated heptanoic acid without co-feeding dihydrogen. ${ }^{12}$ Alpha olefins are valuable commodity chemicals used in the production of plastics, synthetic lubricants, surfactants, and other materials. Carbon-supported Pt and Pd catalysts were shown to be active for the decarbonylation of heptanoic acid but suffered from rapid deactivation at $573 \mathrm{~K}$ and atmospheric pressure. ${ }^{12,13}$ Low selectivity to 1-hexene at high conversions was observed for all tested conditions. Indeed, $20 \%$ selectivity to the desired alpha olefin product was only achieved at conversions below $10 \%$ under vapor phase conditions. The majority of products consisted of internal hexene isomers formed by the rapid isomerization of 1-hexene.

Previous work has shown that Sn can be a beneficial additive to metal catalysts for a range of chemical reactions. ${ }^{14-20}$ Electronic effects have been observed in metal-Sn alloys resulting in a decreased heat of adsorption for $\mathrm{CO}^{21}$ These reported electronic effects may help decrease the rate of deactivation due to self-poisoning. ${ }^{22}$ Furthermore, Chiappero et al. have demonstrated that Pt alloyed with Sn can improve the selectivity to alpha olefins formed during the deoxygenation of methyl esters under semi-batch conditions at temperatures ranging from $593 \mathrm{~K}$ to $623 \mathrm{~K}$ and pressures ranging from 0.2 MPa to $1.14 \mathrm{MPa} .^{23}$ Alpha olefin selectivity improved from $6.5 \%$ over Pt to $23 \%$ over PtSn at $623 \mathrm{~K}$.

In the present study, vapor phase deoxygenation of heptanoic acid was investigated over Pd and PdSn catalysts. In particular, the stability of the catalysts and the selectivity to higher value products without co-fed dihydrogen were explored. Physical mixtures and two stage catalyst beds were also examined to probe the influence of Sn proximity on the reactivity of Pd nanoparticles. Advanced microscopy techniques and X-ray absorption near-edge structure (XANES) spectroscopy were utilized to characterize the catalysts.

\section{Experimental Methods}




\subsection{Catalyst synthesis}

Two $\mathrm{Pd} / \mathrm{SiO}_{2}$ catalyst samples of nominally $5 \mathrm{wt} \%$ each were prepared by ion exchange (IE) or incipient wetness impregnation (IWI) of the Pd precursor using Davisil 636 silica (Sigma-Aldrich) as a support. A high dispersion $\mathrm{Pd} / \mathrm{SiO}_{2}$ sample, denoted as $\mathrm{Pd} / \mathrm{SiO}_{2}-\mathrm{H}$, was synthesized via IE using methods modified from a previously described procedure. ${ }^{24}$ For example, the $\mathrm{PdCl}_{2}$ precursor $(0.510 \mathrm{~g}, 99 \%$, Sigma-Aldrich) was dissolved in a solution of aqueous ammonia $\left(5.428 \mathrm{~cm}^{3}\right.$ ammonium hydroxide, ACS plus, Fisher Scientific, in $282 \mathrm{~cm}^{3}$ distilled deionized water). The metal solution was added dropwise over $10 \mathrm{~min}$ to $5.70 \mathrm{~g}$ of acid-washed Davisil 636 silica in $114 \mathrm{~cm}^{3}$ of distilled deionized water at $343 \mathrm{~K}$. The metal salt and silica slurry was stirred for $60 \mathrm{~min}$ at $343 \mathrm{~K}$, and then cooled to room temperature. The mixture was washed with water and vacuum dried overnight. After calcination in flowing air (medical grade, GTS-Welco) at $673 \mathrm{~K}$ for $2 \mathrm{~h}$, the sample was pre-reduced in flowing $\mathrm{H}_{2}(99.999 \%, \mathrm{GTS}-$ Welco) at $623 \mathrm{~K}$ for $2 \mathrm{~h}$. A low dispersion $\mathrm{Pd} / \mathrm{SiO}_{2}$ sample, denoted as $\mathrm{Pd} / \mathrm{SiO}_{2}-\mathrm{L}$, was prepared via incipient wetness impregnation (IWI) with 10 wt\% $\mathrm{Pd}\left(\mathrm{NO}_{3}\right)_{2} \bullet 4 \mathrm{NH}_{3}$ in $\mathrm{H}_{2} \mathrm{O}$ (99.99\%, Sigma-Aldrich), which was further diluted in water prior to impregnation. The sample was calcined in flowing air (medical grade, GTS-Welco) at $673 \mathrm{~K}$ for $2 \mathrm{~h}$, and pre-reduced at $623 \mathrm{~K}$ in flowing $\mathrm{H}_{2}(99.999 \%$, GTS-Welco) for $2 \mathrm{~h}$.

A Sn/SiO 2 catalyst sample with nominally 5.6 wt\% $\mathrm{Sn}$ was also prepared by IWI using $\mathrm{SnCl}_{2}(98 \%$, Sigma Aldrich) dissolved in water, calcined in flowing air (medical grade, GTS-Welco) at $673 \mathrm{~K}$ for $2 \mathrm{~h}$ and pre-reduced at $623 \mathrm{~K}$ in flowing $\mathrm{H}_{2}(99.999 \%$, GTS-Welco) for $2 \mathrm{~h}$.

Two types of $\mathrm{PdSn} / \mathrm{SiO}_{2}$ samples were prepared. First, $\mathrm{Sn}$ was chemically added to a $\mathrm{Pd} / \mathrm{SiO}_{2}-\mathrm{H}$ sample containing nominally $2.5 \mathrm{wt} \% \mathrm{Pd}$ by the incipient wetness impregnation method using an aqueous solution of $\mathrm{SnCl}_{2}$. After $\mathrm{Sn}$ impregnation, the $\mathrm{PdSn}$ sample was calcined and pre-reduced using the same procedure as the $\mathrm{Sn} / \mathrm{SiO}_{2}$ catalyst. This chemically-mixed sample was denoted as $\mathrm{PdSn} / \mathrm{SiO}_{2}-\mathrm{C}$. The chemically-mixed $\mathrm{Pd}-\mathrm{Sn} / \mathrm{SiO}_{2}-\mathrm{C}$ sample was prepared with a 1:1 atomic ratio of $\mathrm{Pd}: \mathrm{Sn}$ having a nominal Pd loading of $2.5 \mathrm{wt} \%$ and a nominal Sn loading of $2.8 \mathrm{wt} \%$. To prepare a second Sn and Pd 
loaded catalyst, the $\mathrm{Sn} / \mathrm{SiO}_{2}$ sample $\left(5.6 \mathrm{wt} \% \mathrm{Sn}\right.$ ) was mechanically mixed with the $\mathrm{Pd} / \mathrm{SiO}_{2}-\mathrm{H}$ until a uniform mixture was produced. The physically-mixed bimetallic catalyst, denoted as $\mathrm{PdSn} / \mathrm{SiO}_{2}-\mathrm{P}$, was prepared with a 1:1 atomic ratio of Pd:Sn having a nominal Pd loading of 2.5 wt\% and a Sn loading of 2.8 wt\%. All thermal treatments utilized a temperature ramp rate of $1 \mathrm{~K} \mathrm{~min}^{-1}$.

\subsection{Dihydrogen chemisorption}

The number of available metal surface sites was determined using $\mathrm{H}_{2}$ chemisorption on a Micromeritics ASAP 2020 adsorption system. Each catalyst sample was evacuated for $10 \mathrm{~h}$ at $573 \mathrm{~K}$ followed by reduction at $623 \mathrm{~K}$ in flowing $\mathrm{H}_{2}(99.999 \%$, GTS-Welco) for $1 \mathrm{~h}$. After reduction, the system was evacuated and cooled to $373 \mathrm{~K}$ for analysis. The number of available metal sites was determined by extrapolating the high pressure, linear portion of the isotherm to zero pressure. At $373 \mathrm{~K}$, the stoichiometric ratio of $\mathrm{H}$ to surface $\mathrm{Pd}$ is $1: 1 .^{13,25}$

\subsection{X-ray diffraction}

Powder X-ray diffraction (XRD) patterns were measured on a PANalytical X'Pert Pro equipped with monochromatic Cu K $\alpha$-radiation $\left(\lambda=1.54056 \AA\right.$ ) using a step size of $0.0167113^{\circ}$.

\subsection{Transmission electron microscopy}

The high resolution transmission electron microscopy (HR-TEM) and scanning transmission electron microscopy (STEM) utilized in the line scan analysis and energy dispersive spectroscopy (STEMEDS) maps were performed on an FEI Titan 80-300 operating at $300 \mathrm{kV}$ that is equipped with a Gatan 794 Multi-scan Camera (EFTEM) and an energy dispersive spectrometer for X-ray elemental analysis. Samples analyzed on the FEI Titan 80-300 were prepared by dispersing catalyst samples in cyclohexane and mounted on holey carbon grids. 
Samples for selected area EDS composition analysis were dispersed in ethanol and mounted on holey carbon grids for examination in a JEOL 2010F $200 \mathrm{kV}$ scanning transmission electron microscope equipped with an Oxford Aztec Energy Dispersive System for elemental analysis. Images were recorded in high angle annular dark field (HAADF) mode. Elemental compositions were acquired in selected regions of the sample, as indicated by "boxes" shown in the HAADF-STEM image.

\subsection{X-ray absorption near-edge structure}

The in situ Sn K-edge X-ray absorption near-edge structure (XANES) analysis during temperature programmed reduction (TPR) in $\mathrm{H}_{2}$ was conducted at the $8 \mathrm{C}$ beamline in the Pohang Light Source (PLS) operating with a $3.0 \mathrm{GeV}$ ring energy and a $300 \mathrm{~mA}$ ring current. A Si (1 111 ) double crystal monochromator was employed to vary the X-ray photon energy. The XANES spectra were obtained in the transmission mode using ionization gas chambers to detect the primary $\left(I_{0}, 100 \% N_{2}\right)$ and the transmitted ( $I_{t} 70 \% N_{2}$, balance Ar) beam intensities. Higher order harmonic contamination was eliminated by detuning the monochromator to reduce the incident X-ray intensity by about $30 \%$. Energy calibration was performed using a standard Sn foil. A self-supported catalyst wafer was loaded into an in situ quartz reactor with a $25.4 \mathrm{~mm}$ external diameter. A quartz sample holder with a $15 \mathrm{~mm}$ external diameter was positioned in the center of the reactor with a thermocouple port located just about the sample. A mixture of $5 \% \mathrm{H}_{2}$ in $\mathrm{He}$ flowed at $100 \mathrm{~cm}^{3} \mathrm{~min}^{-1}$ while the temperature ramped at $5 \mathrm{~K} \mathrm{~min}^{-1}$ from room temperature to $673 \mathrm{~K}$. The catalysts examined by XANES were unreduced samples of $\mathrm{Sn} / \mathrm{SiO}_{2}$, $\mathrm{PdSn} / \mathrm{SiO}_{2}-\mathrm{C}$, and $\mathrm{PdSn} / \mathrm{SiO}_{2}-\mathrm{P}$. The relative white line intensity of each $\mathrm{Sn}$ sample during $\mathrm{H}_{2}-\mathrm{TPR}$ was calculated on the basis of the normalized edge jump of Sn foil using: $I_{r}=I$ (SnOx sample) $/ I_{o}$ (Sn foil).

The in situ Sn K-edge XANES spectra were also collected during butyric acid (99+\%, Alfa Aesar) deoxygenation at the same beamline. Butyric acid was chosen as the probe molecule because of its high vapor pressure relative to heptanoic acid. A catalyst sample was pressed into a wafer that was placed 
directly in the quartz sample holder described above and reduced in situ in $100 \mathrm{~cm}^{3} \mathrm{~min}^{-1} 5 \% \mathrm{H}_{2} / \mathrm{He}$ during a heating ramp of $10 \mathrm{~K} \mathrm{~min}^{-1}$ to a temperature of $623 \mathrm{~K}$, after which the temperature was constant for $30 \mathrm{~min}$ before cooling to the reaction temperature of $573 \mathrm{~K}$. Dinitrogen flowing at $500 \mathrm{~cm}^{3}$ $\mathrm{min}^{-1}$ was bubbled through liquid butyric acid maintained at room temperature and the mixture was fed to the catalyst held at $573 \mathrm{~K}$ for XANES collection. The TPR results were processed using WinXAS 3.1 software and the in situ deoxygenation reaction results were processed using Athena software.

\subsection{Catalytic deoxygenation of heptanoic acid}

Catalysts were evaluated for activity in the deoxygenation of heptanoic acid in a continuous upward flow reactor as described previously. ${ }^{12}$ In summary, the reactor consisted of a $0.64 \mathrm{~cm}$ OD x $0.089 \mathrm{~cm}$ wall thickness stainless steel tube that is $15 \mathrm{~cm}$ in length. A pre-heating section of the same material was $10 \mathrm{~cm}$ in length. Glass wool was placed above and below the catalyst to maintain the position of the bed. Aluminum heating jackets surrounded the reactor and pre-heating section to facilitate uniform heat transfer.

A liquid feed consisting of 95 wt\% heptanoic acid (>98\%, Sigma-Aldrich) and 5 wt\% dodecane (>99\%, Sigma-Aldrich) was pumped from an ISCO 500D syringe pump into the pre-heating section where the feed was vaporized. Dodecane was included in the feed as an internal standard.

The catalysts were reduced in situ with $150 \mathrm{~cm}^{3} \mathrm{~min}^{-1} \mathrm{H}_{2}(99.999 \%, \mathrm{GTS}-$ Welco) at $623 \mathrm{~K}$ for $2 \mathrm{~h}$ after heating with a ramp rate of $1 \mathrm{~K} \mathrm{~min}^{-1}$. The reactor was then cooled to $573 \mathrm{~K}$ and purged with 200 $\mathrm{cm}^{3} \min ^{-1} \mathrm{~N}_{2}(99.999 \%$, GTS-Welco) for $1 \mathrm{~h}$.

Liquid-phase products were separated in a condenser positioned above the outlet of the reactor. Initial time on stream was defined as the time which liquid began to enter the condenser. Gaseous products were continuously removed by a $7 \mathrm{~cm}^{3} \mathrm{~min}^{-1}$ purge of $\mathrm{N}_{2}(99.999 \%$, GTS-Welco) through the condenser and fed to an on-line HP 5890 Series II gas chromatograph equipped with a 
ShinCarbon 80/100 packed column and a thermal conductivity detector (TCD). Liquid-phase products were analyzed using an Agilent 7890 gas chromatograph equipped with a ZB-FFAP column and a flame ionization detector (FID).

Using the mass transfer criteria on the conversion of heptanoic acid over supported Pt catalysts described in a previously published paper ${ }^{12}$, we verified the lack of internal and external mass transfer effects on the measured rates over the supported $\mathrm{PdSn} / \mathrm{SiO}_{2}$ catalysts used in the current work.

\subsection{Calculation of rates and selectivity}

Conversion was defined as the total rate of formation of the deoxygenation products divided by the molar feed rate of reagent as shown in Eq. 1. In this work, conversion was always less than $20 \%$.

$$
\begin{gathered}
\text { Conversion }=(\text { total molar formation rate of hexane }+1 \text {-hexene }+i \text {-hexene }+ \text { heptanal }+ \text { hexadiene }+2 \\
* \text { tridecanone }+ \text { unknown }) /(\text { molar rate of heptanoic acid fed })
\end{gathered}
$$

A blank run with $\mathrm{SiO}_{2}$ support revealed a background conversion that was below $0.1 \%$, and thus background conversion was neglected in this study. The reaction rate over monometallic Pd catalysts was reported as a turnover frequency (TOF), or reaction rate normalized by the number of available surface sites, to properly account for the difference in Pd particle size between the samples. We assumed that the particle size of the active Pd catalyst was equal to the size measured on fresh catalyst sample. The TOF $\left(\mathrm{s}^{-1}\right)$ is therefore calculated according to Eq. 2.

$$
\text { TOF }=\text { Conversion } * \frac{\text { molar rate of heptanoic acid fed }}{\text { moles of surface metal }}
$$

Liquid product selectivities were defined by molar rates of product formation divided by total molar rate of formation of all products as shown in Eq. 3.

$$
\text { Selectivity }=\frac{\text { molar rate of formation of product, } x_{i}}{\text { total molar rate of formation of products, } \sum x_{i}}
$$


Gas phase products, consisting of $\mathrm{CO}$ and $\mathrm{CO}_{2}$, were measured relative to a $\mathrm{N}_{2}$ standard and reported as the \% $\mathrm{CO}$ in the product gas, defined by Eq. 4.

$$
\% \mathrm{CO}=\frac{\mathrm{CO}}{\mathrm{CO}+\mathrm{CO}_{2}} * 100
$$

\section{Results}

\subsection{Physical properties of $\mathrm{Pd} / \mathrm{SiO}_{2}$ and $\mathrm{PdSn} / \mathrm{SiO}_{2}$ catalysts}

Physical properties of the catalyst samples, including results from $\mathrm{H}_{2}$ chemisorption and particle size analysis via electron microscopy, are summarized in Table 1 . The $\mathrm{Pd} / \mathrm{SiO}_{2}-\mathrm{H}$ catalyst prepared by the IE method exhibited the highest $\mathrm{H} / \mathrm{Pd}$ ratio of 0.80 followed by $\mathrm{Pd} / \mathrm{SiO}_{2}-\mathrm{L}(\mathrm{H} / \mathrm{Pd}=0.32)$. Only $6.1 \%$ of the $\mathrm{Pd}$ was exposed in the $\mathrm{PdSn} / \mathrm{SiO}_{2}-\mathrm{C}$ despite utilizing the same $\mathrm{Pd}$ deposition method to prepare $\mathrm{Pd} / \mathrm{SiO}_{2}$ $\mathrm{H}$. The $\mathrm{PdSn} / \mathrm{SiO}_{2}-\mathrm{P}$ sample mixture also exhibited a decrease in exposed $\mathrm{Pd}$ when the sample was reduced at $623 \mathrm{~K}$ in flowing $\mathrm{H}_{2}$ prior to $\mathrm{H}_{2}$ chemisorption $(\mathrm{H} / \mathrm{Pd}=0.51)$. No chemisorbed hydrogen was detected on $\mathrm{Sn} / \mathrm{SiO}_{2}$.

Figure 1 presents dark field STEM images of the fresh monometallic Pd and Sn catalysts. The STEM images for $\mathrm{Pd} / \mathrm{SiO}_{2}-\mathrm{L}$ and $\mathrm{Pd} / \mathrm{SiO}_{2}-\mathrm{H}$ show well-dispersed nanoparticles in size ranges of $2.4 \pm 0.5$ and $1.1 \pm 0.4 \mathrm{~nm}$, respectively. As for the $\mathrm{Sn} / \mathrm{SiO}_{2}$ sample, individual nanoparticles were not observed in STEM, but the EDS results confirmed the presence of Sn (not shown) suggesting that Sn may be dispersed as single atoms on $\mathrm{SiO}_{2} \cdot{ }^{26}$ Despite depositing the $\mathrm{Pd}$ using a technique shown to produce welldispersed nanoparticles, ${ }^{24,27-29}$ a low amount of $\mathrm{Pd}$ was exposed to the gas phase in the $\mathrm{PdSn} / \mathrm{SiO}_{2}-\mathrm{C}$ catalyst. Moreover, a variety of particle sizes was observed in STEM images, ranging from $1 \mathrm{~nm}$ to 100 $\mathrm{nm}$ (Fig. S1). Drift-corrected EDS line scans were used to characterize the large particles, defined as those in excess of $75 \mathrm{~nm}$, in both the fresh and used catalyst samples. Those results, presented in Fig. S2, indicate the presence of both Pd and Sn in the fresh and used samples.

The samples were examined by X-ray diffraction and no features associated with metal particles were detected on the fresh and used monometallic $\mathrm{Pd} / \mathrm{SiO}_{2}-\mathrm{H}$ catalyst. Figure 2 shows the powder X-ray 
diffraction patterns of fresh and used $\mathrm{PdSn} / \mathrm{SiO}_{2}-\mathrm{C}$ together with the positions of selected peaks from reference Pd (JCDPS 00-005-0681), $\mathrm{Pd}_{3} \mathrm{Sn}_{2}$ (JCPDS 00-007-0170), and $\mathrm{Pd}_{2} \mathrm{Sn}$ (JCPDS 00-026-1297). In contrast to the results from monometallic $\mathrm{Pd} / \mathrm{SiO}_{2}-\mathrm{H}$, distinct XRD peaks were observed with fresh and used $\mathrm{PdSn} / \mathrm{SiO}_{2}-\mathrm{C}$ catalysts. The fresh $\mathrm{PdSn} / \mathrm{SiO}_{2}-\mathrm{C}$ catalyst exhibited a broadened feature with components at $39.4^{\circ}, 40.2^{\circ}$, and $40.7^{\circ}$. The feature positions are close to characteristic XRD peaks of reference $\mathrm{Pd}, \mathrm{Pd}_{3} \mathrm{Sn}_{2}$, and $\mathrm{Pd}_{2} \mathrm{Sn}$. Used $\mathrm{PdSn} / \mathrm{SiO}_{2}-\mathrm{C}$ exhibited a weak feature at $39.4^{\circ}$ characteristic of $\mathrm{Pd}_{2} \mathrm{Sn}$.

The STEM-HAADF images and results from EDS analyses of a fresh physical mixture of Pd and Sn, denoted as $\mathrm{PdSn} / \mathrm{SiO}_{2}-\mathrm{P}$, can be found in the supplemental materials (Fig. S3). The EDS results of the fresh catalyst sample indicate Pd and Sn are not present on the same support particles. Clearly, the Pd nanoparticles and the Sn species reside on different silica support particles prior to being subjected to reaction conditions, including pre-reduction. The EDS analysis of used $\mathrm{PdSn} / \mathrm{SiO}_{2}-\mathrm{P}$ confirmed the physical migration of $\mathrm{Sn}$ after the catalyst was subjected to in situ pre-reduction and reaction conditions (Fig. S4 and S5). Both Pd and Sn can be found in the same regions of the used catalysts, as well as on the same support particle (Fig. 3). The 3-D STEM-EDS maps (Fig. 3) of Pd and Sn illustrate the co-location of the metals with respect to each other in the used $\mathrm{PdSn} / \mathrm{SiO}_{2}-\mathrm{P}$ sample. A 3-D STEM-EDS map (Fig. 4) of used $\mathrm{PdSn} / \mathrm{SiO}_{2}-\mathrm{C}$, formed by IWI of $\mathrm{Sn}$ on $\mathrm{Pd} / \mathrm{SiO}_{2}$, is included for comparison.

\subsection{Catalytic activity in deoxygenation of heptanoic acid}

\subsubsection{Particle size effect}

Metal particle size is correlated to the stability of catalytic Pd nanoparticles during deoxygenation reactions of fatty acids when an excess of $\mathrm{H}_{2}$ is present. ${ }^{11}$ In this study, Pd catalysts with particles differing in size by about a factor of 2 are compared in an environment devoid of excess co-fed $\mathrm{H}_{2}$. The conversion of heptanoic acid with time over $\mathrm{Pd} / \mathrm{SiO}_{2}-\mathrm{L}$ and $\mathrm{Pd} / \mathrm{SiO}_{2}-\mathrm{H}$ is shown in Fig. 5a. Both 
catalysts achieved similar peak conversion of about $17-18 \%$ after $1.5 \mathrm{~h}$ on stream. The $\mathrm{Pd} / \mathrm{SiO}_{2}-\mathrm{H}$ catalyst maintained higher conversion after $10 \mathrm{~h}$, exhibiting a $12 \%$ conversion of heptanoic acid compared to 4.2\% conversion over the $\mathrm{Pd} / \mathrm{SiO}_{2}-\mathrm{L}$ catalyst. At the observed peak of activity, $1.5 \mathrm{~h}$ on stream, the $\mathrm{Pd} / \mathrm{SiO}_{2}-\mathrm{L}$ had a TOF of $0.0045 \mathrm{~s}^{-1}$ compared to $\mathrm{Pd} / \mathrm{SiO}_{2}-\mathrm{H}$, which had a TOF of $0.0027 \mathrm{~s}^{-1}$. After $10 \mathrm{~h}$ on stream, the TOF exhibited by $\mathrm{Pd} / \mathrm{SiO}_{2}-\mathrm{L}$ had decreased by $71 \%$ to $0.0013 \mathrm{TOF} \mathrm{s}{ }^{-1}$. The TOF over $\mathrm{Pd} / \mathrm{SiO}_{2}-\mathrm{H}$ decreased by $33 \%$ to $0.0018 \mathrm{~s}^{-1}$ after $10 \mathrm{~h}$. Evidently initial rate and catalyst stability are inversely related in this system.

Product distributions characteristic of each monometallic Pd catalyst can be found in Fig. $5 \mathrm{c}$ and $5 \mathrm{~d}$. The primary liquid phase $\left(\mathrm{C}_{6}\right)$ product formed over both Pd catalysts is hexene, but more than $70 \%$ of these olefinic products are 2 and 3-hexene (i-hexene), while approximately $10 \%$ of the product is 1 hexene. Higher selectivity to 1-hexene, the direct alpha olefin product from decarbonylation of heptanoic acid, is favored at lower conversions, which is consistent with previous studies by Lopez-Ruiz et al. ${ }^{12,13}$ The $\%$ CO was measured at $0.5 \mathrm{~h}$ time on stream and after $10 \mathrm{~h}$ time on stream (Table 2). The total olefin selectivity (1-hexene+i-hexene) is expected to match the \%CO in the gas phase products as both are a result of decarbonylation. The \%CO observed at $0.5 \mathrm{~h}$ and after $10 \mathrm{~h}$ time on stream for both the $\mathrm{Pd} / \mathrm{SiO}_{2}-\mathrm{L}$ and $\mathrm{Pd} / \mathrm{SiO}_{2}-\mathrm{H}$ are consistent with the observed liquid phase products, i.e. decarbonylation was the primary reaction path over $\mathrm{Pd}$.

\subsubsection{Effect of $\mathrm{Sn}$ addition}

Monometallic $\mathrm{Sn} / \mathrm{SiO}_{2}$ was relatively inactive in heptanoic acid conversion under the examined reaction conditions at metal loadings comparable to the $\mathrm{Pd} / \mathrm{SiO}_{2}$ experiments. For example, conversion of heptanoic acid after $3 \mathrm{~h}$ of time on stream was $0.55 \%$, approximately $0.5 \%$ higher than the background conversion over silica. The primary product over $\mathrm{Sn} / \mathrm{SiO}_{2}$ was 7-tridecanone with a selectivity of $67 \%$. Heptanal, hexadiene, hexane and 1-hexene were the other primary products with 
selectivities of $9.7 \%, 8.4 \%, 7.4 \%$, and $4.4 \%$, respectively. The remaining $3.1 \%$ consisted of an unknown product. A complete summary of the product distribution formed over $\mathrm{Sn} / \mathrm{SiO}_{2}$ can be found in Fig. S6.

The addition of Sn to $\mathrm{Pd}$ may have improved the stability of $\mathrm{Pd}$ under the deoxygenation conditions utilized in this study (Fig. 6), but the conversions were not consistent between the catalysts. Most importantly, $\mathrm{PdSn} / \mathrm{SiO}_{2}-\mathrm{C}$ maintained relatively constant $8 \%$ conversion of heptanoic acid after the usual initial break-in period. Likewise, the physical mixture $\mathrm{PdSn} / \mathrm{SiO}_{2}-\mathrm{P}$ exhibited a similar level of activity and stability as the bimetallic $\mathrm{PdSn} / \mathrm{SiO}_{2}-\mathrm{C}$ catalyst, converting $7 \%$ of heptanoic acid after more than $10 \mathrm{~h}$ time on stream. An additional test involving a physical mixture of $\mathrm{Pd} / \mathrm{SiO}_{2}-\mathrm{H}$ and bare silica, containing the same amount of $\mathrm{Pd} / \mathrm{SiO}_{2}$ as $\mathrm{PdSn} / \mathrm{SiO}_{2}-\mathrm{P}$ and denoted as $\mathrm{Pd} / \mathrm{SiO}_{2}-\mathrm{D}$, was evaluated to ensure that the activity and stability of the physical and chemical mixtures of Pd and Sn was the result of Sn and not the low TOF associated with $\mathrm{Pd} / \mathrm{SiO}_{2}-\mathrm{H}$. The dilution of $\mathrm{Pd} / \mathrm{SiO}_{2}-\mathrm{H}$ with bare silica, $\mathrm{Pd} / \mathrm{SiO}_{2}-\mathrm{D}$, did not alter the product selectivity associated with the monometallic Pd during conversion of heptanoic acid. As shown in Fig. 6a, the deactivation observed for $\mathrm{Pd} / \mathrm{SiO}_{2}-\mathrm{D}$, which was tested at the same level of conversion as the Sn-promoted catalysts, confirms the positive effect of $\mathrm{Sn}$ on stabilizing the Pd catalysts.

The addition of $\mathrm{Sn}$ to a Pd catalyst significantly altered the product distribution observed over monometallic Pd during heptanoic acid conversion. The reaction over $\mathrm{PdSn} / \mathrm{SiO}_{2}-\mathrm{C}$ (Fig. 6b) produced 7tridecanone, formed via decarboxylative ketonization, as a major product with a selectivity of $38 \%$ at 0.5 h time on stream. Heptanal, formed via dehydration, was also produced with a selectivity of $28 \%$ at 0.5 $\mathrm{h}$ time on stream. The selectivities to 1 -hexene, i-hexene, hexadiene, and hexane were $3.7 \%, 2.3 \%, 1.2 \%$, and $1.2 \%$, respectively. An unknown product was detected at $0.5 \mathrm{~h}$ time on stream with a selectivity of $25 \%$, assuming a similar response factor, but the selectivity decreased to $2 \%$ after $2 \mathrm{~h}$. As the time on stream increased to $10.75 \mathrm{~h}$, the selectivity to 7 -tridecanone decreased to $12 \%$ and the selectivity to heptanal increased to $36 \%$. Roughly equal amounts of 1 -hexene and i-hexene were produced with 
selectivities of $18 \%$ and $22 \%$, respectively, and hexadiene was produced with a selectivity of $5.9 \%$. Interestingly, hexane was not produced in significant quantities after $10.75 \mathrm{~h}$ time on stream.

Initially, the physical mixture of $\mathrm{PdSn} / \mathrm{SiO}_{2}-\mathrm{P}$ (Fig. 6c) had a product distribution that was largely characteristic of $\mathrm{Pd} / \mathrm{SiO}_{2}$-catalyzed heptanoic acid deoxygenation. More than $80 \%$ of the initial products were consistent with a monometallic $\mathrm{Pd} / \mathrm{SiO}_{2}$ catalyst, with 7-tridecanone making up the balance. The product distribution changed with time on stream until the selectivity patterns of $\mathrm{PdSn} / \mathrm{SiO}_{2}-\mathrm{P}$ and the $\mathrm{PdSn} / \mathrm{SiO}_{2}-\mathrm{C}$ catalysts were nearly identical. Heptanal was the primary deoxygenated product over the $\mathrm{PdSn} / \mathrm{SiO}_{2}-\mathrm{P}$ catalyst with a selectivity of $42 \%$. Internal double bond isomers of hexene comprised $14 \%$ of the products while 1 -hexene was $18 \%$. The 7 -tridecanone product accounted for $15 \%$ whereas hexadiene was $9.0 \%$ of the products.

The $\% \mathrm{CO}$ in the gas phase products observed during the conversion of heptanoic acid over the $\mathrm{PdSn} / \mathrm{SiO}_{2}-\mathrm{C}$ and $\mathrm{PdSn} / \mathrm{SiO}_{2}-\mathrm{P}$ catalysts is shown in Table 2. The \%CO observed over both $\mathrm{PdSn}$ catalysts after $10 \mathrm{~h}$ on stream did not match well the selectivity to decarbonylation products. The explanation for the lower than anticipated \%CO observed is unknown, but it might indicate some conversion of $\mathrm{CO}$ to $\mathrm{CO}_{2}$ via the water-gas-shift reaction.

\subsection{Effect of Sn proximity to Pd}

To further probe the promotional effect of $\mathrm{Sn}$ on $\mathrm{Pd}$, heptanoic acid was passed through a reactor containing a $\mathrm{Pd} / \mathrm{SiO}_{2}-\mathrm{H}$ section and a $\mathrm{Sn} / \mathrm{SiO}_{2}$ section separated by glass wool to ensure there was no direct contact between the supported catalysts. The two different catalyst bed configurations that were tested are illustrated in Fig. 7a. The configurations are designated as $M_{1} / M_{2}$ where $M_{1}$ was the catalyst at the bottom of the reactor and was the first to contact the heptanoic acid feed.

The general shape of the conversion curves for both configurations (Fig. 7b) is nearly identical to $\mathrm{Pd} / \mathrm{SiO}_{2}-\mathrm{H}$ (Fig. 5a) in which there is an increase in conversion to a maximum followed by deactivation. 
When heptanoic acid contacted the Pd catalyst first $(\mathrm{Pd} / \mathrm{Sn})$, the product distribution reported in Fig. 7c resembled that from a reaction catalyzed by a monometallic $\mathrm{Pd} / \mathrm{SiO}_{2}$ catalyst. Most importantly, 7tridecanone and heptanal were not observed in the reaction products.

The configuration in which the heptanoic acid contacted $\mathrm{Sn} / \mathrm{SiO}_{2}$ prior to $\mathrm{Pd} / \mathrm{SiO}_{2}(\mathrm{Sn} / \mathrm{Pd})$ exhibited greater conversion of heptanoic acid compared to the $\mathrm{Pd} / \mathrm{Sn}$ configuration (Fig. $7 \mathrm{~b}$ ). The greater heptanoic acid conversion when it contacts the Sn catalyst first is reflected in a new product distribution (Fig. 7d). For the Sn/Pd configuration, 7-tridecanone was formed at a selectivity of 30\% after $10.75 \mathrm{~h}$ on stream, whereas i-hexene selectivity was only $42 \%$. The selectivity to 1 -hexene and hexane remained largely unchanged from those produced over the $\mathrm{Pd} / \mathrm{Sn}$ configuration at 11 and $14 \%$, respectively.

The percent of $\mathrm{CO}$ in the gas phase from each catalyst bed configuration is presented in Table 3. The \% $\mathrm{CO}$ is largely consistent with the measured amounts of decarbonylation products versus decarboxylative ketonization product.

\subsection{In situ XANES analysis}

Figure 8 shows the Sn K-edge XANES spectra collected over the course of $\mathrm{H}_{2}$ TPR for $\mathrm{Sn} / \mathrm{SiO}{ }_{2}, \mathrm{PdSn}_{\mathrm{SiO}}{ }_{2}^{-}$ C, and $\mathrm{PdSn} / \mathrm{SiO}_{2}-\mathrm{P}$ catalysts. Compared to bulk $\mathrm{SnO}_{2}{ }^{30}$, which has an $\mathrm{E}_{\mathrm{o}}$ at $29.2053 \mathrm{keV}$, all the unreduced catalyst samples present a very similar spectrum with an identical $E_{0}$ white line intensity at $298 \mathrm{~K}$, indicating that the oxidation state of $\mathrm{Sn}$ in the samples is close to that of $\mathrm{SnO}_{2}$. During the temperature ramp in flowing $5 \% \mathrm{H}_{2} / \mathrm{He}$, the XANES spectrum of $\mathrm{Sn} / \mathrm{SiO}_{2}$ revealed a gradual decrease in the white line intensity up to $508 \mathrm{~K}$ (Figs. $8 \mathrm{a}$ and 8d), indicating a partial reduction of the supported $\mathrm{SnO}_{2}$. Addition of $\mathrm{Pd}$, i.e. in $\mathrm{PdSn} / \mathrm{SiO}_{2}-\mathrm{C}$, promoted a more extensive reduction of the $\mathrm{SnO}_{2}$ as evidenced by a more substantial decrease in the white line intensity (Figs. 8b and 8d) and likely caused by hydrogen spill-over ${ }^{31}$. The white line intensities associated with the physically mixed $\mathrm{PdSn} / \mathrm{SiO}_{2}-\mathrm{P}$ catalyst were 
positioned between those of $\mathrm{Sn} / \mathrm{SiO}_{2}$ and $\mathrm{PdSn} / \mathrm{SiO}_{2}-\mathrm{C}$ (Figs. $8 \mathrm{c}$ and $8 \mathrm{~d}$ ).

Figure 9 presents the in situ XANES spectra for $\mathrm{PdSn} / \mathrm{SiO}_{2}-\mathrm{C}$ and $\mathrm{PdSn} / \mathrm{SiO}_{2}-\mathrm{P}$ catalysts during butyric acid conversion at 573K. The XANES spectrum of $\mathrm{PdSn} / \mathrm{SiO}_{2}-\mathrm{P}$ in the presence of butyric acid remained unchanged from that of pre-reduced $\mathrm{PdSn} / \mathrm{SiO}_{2}-\mathrm{P}$, indicating the $\mathrm{Sn}$ species present under reaction conditions are likely partially reduced oxides (Fig. 9b). The lower intensity of the white line in the XANES spectrum of pre-reduced $\mathrm{PdSn} / \mathrm{SiO}_{2}-\mathrm{C}$ (Fig. 9a) compared to $\mathrm{PdSn} / \mathrm{SiO}_{2}-\mathrm{P}$ (Fig $11 \mathrm{~b}$ ) indicates the $\mathrm{Sn}$ species is more reduced in $\mathrm{PdSn} / \mathrm{SiO}_{2}-\mathrm{C}$. The presence of butyric acid, however, slightly increased the white line intensity of $\mathrm{PdSn} / \mathrm{SiO}_{2}-\mathrm{C}$ resulting in an $\mathrm{E}_{\mathrm{o}}$ that was very close to that of $\mathrm{PdSn} / \mathrm{SiO}_{2}-\mathrm{P}$ catalyst (Fig. 9b). Thus, the chemical state of the $\mathrm{Sn}$ in the bimetallic catalyst during reaction is similar to that of the physical mixture.

\section{Discussion}

\subsection{Structural properties of Pd, Sn, and PdSn catalysts}

The lack of XRD features associated with the monometallic catalysts is consistent with the very high dispersion of the $\mathrm{Pd} / \mathrm{SiO}_{2}$ and the $\mathrm{Sn} / \mathrm{SiO}_{2}$ samples. In contrast, XRD features were observed for both the fresh and used $\mathrm{PdSn} / \mathrm{SiO}_{2}-\mathrm{C}$ catalyst, as illustrated in Fig. 2. The expected $\mathrm{Pd}$ (111) peak at $40.1^{\circ}$ appeared to be shifted to $39.4^{\circ}$ for the fresh and used $\mathrm{PdSn} / \mathrm{SiO}_{2}-\mathrm{C}$, which is attributed to the substitution of the larger Sn atom into the Pd lattice. Indeed, the peak at $39.4^{\circ}$ is consistent with a

$\mathrm{Pd}_{2} \mathrm{Sn}$ alloy. ${ }^{32}$ An additional peak at $40.7^{\circ}$ is observed in the diffraction pattern of the fresh $\mathrm{PdSn} / \mathrm{SiO}_{2}-\mathrm{C}$ sample, which could suggest a $\mathrm{Pd}_{3} \mathrm{Sn}_{2}$ crystal structure, which exhibits a strong diffraction peak at $41.0^{\circ}$. The peak at $40.7^{\circ}$ is, however, absent in the diffraction pattern of the used $\mathrm{PdSn} / \mathrm{SiO}_{2}-\mathrm{C}$ catalyst.

\subsection{Catalytic performance of Pd, Sn, and PdSn catalysts in deoxygenation of heptanoic acid}

\subsubsection{Activity of Pd catalysts}


Deoxygenation of fatty acids over carbon and silica supported noble metal catalysts, including $\mathrm{Pd}$, has been demonstrated to proceed via decarbonylation and decarboxylation (Schemes $1 \mathrm{~A}$ and

1B)..$^{9,12,13,33}$ In the present study, the high selectivity to olefin products accompanied by formation of $\mathrm{CO}$ indicates that decarbonylation is the primary route of deoxygenation over monometallic $\mathrm{Pd} / \mathrm{SiO}_{2}$ catalysts under the examined reaction conditions. For example, after $10.75 \mathrm{~h}$ on stream, hexenes accounted for $84 \%$ of the hydrocarbon products and the \%CO found in the gas phase product stream was $88 \%$ (Table 2). The other major product formed over $\mathrm{Pd} / \mathrm{SiO}_{2}$ was hexane, with a selectivity of $14 \%$, which corresponds well to the $\% \mathrm{CO}_{2}$ value of $12 \%$. Since the product selectivity exhibited by both monometallic Pd catalysts was similar, the Pd particle size between 1-2 $\mathrm{nm}$ did not affect the preferred reaction path.

In contrast, the particle size influenced the stability and TOF of the $\mathrm{Pd} / \mathrm{SiO}_{2}$ catalyst. Sun et al. observed that larger particles experienced less severe deactivation while converting octanoic acid over $\mathrm{Pd} / \mathrm{SiO}_{2}$ in the presence of dihydrogen. ${ }^{11}$ The opposite result was observed in the current work on conversion of heptanoic acid in absence of dihydrogen. Results in Fig. 5 clearly show the catalyst with larger $\mathrm{Pd}$ particles $\left(\mathrm{Pd} / \mathrm{SiO}_{2}-\mathrm{L}\right)$ deactivating faster than the catalyst with smaller $\mathrm{Pd}$ particles $\left(\mathrm{Pd} / \mathrm{SiO}_{2}-\mathrm{H}\right)$. Smaller Pd particles may deactivate slower because they are catalyzing the reaction at a lower TOF. Lugo-José et al. showed that the TOF for hydrodeoxygenation of propanoic acid over $\mathrm{Pd} / \mathrm{SiO}_{2}$ remains constant when particles are between 3.0-12.4 nm, but decreases by a factor of 2-3 as the Pd particles decreased in size below $3 \mathrm{~nm} \cdot{ }^{34}$ In the present study, lower TOF of the smaller Pd particles may decrease the rate of self-poisoning which is manifested as more stable activity of the catalyst.

\subsubsection{Activity of PdSn catalysts}

The physical mixture of $\mathrm{Pd}$ and $\mathrm{Sn}, \mathrm{PdSn} / \mathrm{SiO}_{2}-\mathrm{P}$, initially exhibited selectivity in heptanoic acid conversion that was characteristic of monometallic $\mathrm{Pd} / \mathrm{SiO}_{2}-\mathrm{H}$. The change in product selectivity over the 
$\mathrm{PdSn} / \mathrm{SiO}_{2}-\mathrm{P}$ from primarily decarbonylation (typical of monometallic $\mathrm{Pd}$ ) to primarily dehydration, decarbonylation and decarboxylative ketonization suggests the catalyst structure changes under reaction conditions. The EDS analysis of used $\mathrm{PdSn} / \mathrm{SiO}_{2}-\mathrm{P}$ indicates the physical migration of $\mathrm{Sn}$ to the silica support particles containing Pd nanoparticles. Treatment in $\mathrm{H}_{2}$ appears to facilitate some of the $\mathrm{Sn}$ migration during the pre-reduction step, as indicated by the decreased $\mathrm{H} / \mathrm{Pd}$ from $\mathrm{H}_{2}$ chemisorption results observed for the $\mathrm{PdSn} / \mathrm{SiO}_{2}-\mathrm{P}$ compared to the $\mathrm{Pd} / \mathrm{SiO}_{2}-\mathrm{H}$. However, the change in product selectivity with time on stream suggests that a more substantial migration occurred when heptanoic acid flowed over the catalyst.

The migrating Sn species during reaction are hypothesized to be volatile tin carboxylates formed via the reaction between $\mathrm{SnO}_{\mathrm{x}}$ species and heptanoic acid. ${ }^{35}$ These tin species may decompose on $\mathrm{Pd}$ sites located on and within nearby silica particles or simply be deposited on the silica support. ${ }^{35}$ The $\mathrm{SnO}_{x}$ species present in the fresh $\mathrm{PdSn} / \mathrm{SiO}_{2}-\mathrm{P}$ catalyst are extremely well dispersed as indicated by the lack of observable particles by HR-TEM. The very low heptanal formation rate observed over the Sn/Pd reactor configuration compared to that observed from the $\mathrm{PdSn} / \mathrm{SiO}_{2}-\mathrm{P}$ and $\mathrm{PdSn} / \mathrm{SiO}_{2}-\mathrm{C}$ catalysts indicates Sn species are incapable of migrating through the glass wool separating the Sn and Pd catalyst beds.

In situ XANES studies suggest that a Pd and Sn bulk alloy is not likely the active phase of the bimetallic system. Migration and redeposition of $\mathrm{Sn}$ in the physical mixture $\mathrm{PdSn} / \mathrm{SiO}_{2}-\mathrm{P}$ forms a partially reduced $\mathrm{SnO}_{\mathrm{x}}$ that was responsible for the production of heptanal under reaction conditions. Metal oxide catalysts possessing moderate strength metal-oxygen bonds, including $\mathrm{Fe}_{2} \mathrm{O}_{3}$ and $\mathrm{SnO}_{2}$, have been shown to be selective for dehydration of carboxylic acids in the presence of $\mathrm{H}_{2}$ through a reverse Mars and Van Krevelen mechanism (Scheme 1D). ${ }^{36-38}$ Addition of a metal capable of hydrogen spillover, such as $\mathrm{Pt}$, facilitates reduction of the metal oxide, thus promoting aldehyde formation. ${ }^{38,39}$ The hydrogen required to form oxygen vacancies may come from the water-gas shift reaction on Pd sites. Such a side 
reaction is consistent with the observed discrepancy of \%CO observed for both $\mathrm{PdSn} / \mathrm{SiO}_{2}-\mathrm{C}$ and $\mathrm{PdSn} / \mathrm{SiO}_{2}-\mathrm{P}$.

The product distribution from heptanoic acid conversion over bimetallic $\mathrm{PdSn} / \mathrm{SiO}_{2}-\mathrm{C}$ changed throughout the course of the $10.75 \mathrm{~h}$ run. The XRD patterns for the fresh and used bimetallic catalyst indicate a change in crystal structure of the metal particles after exposure to reaction conditions. Nevertheless, the in situ XANES study of $\mathrm{PdSn} / \mathrm{SiO}_{2}-\mathrm{C}$ during butyric acid conversion confirms partially reduced $\mathrm{SnO}_{x}$ species are similar to those present on the physical mixture. Carboxylic acids containing two $\alpha$-hydrogens, such as heptanoic acid, will undergo decarboxylative ketonization on metal oxide surfaces that do not contain a prevalence of oxygen vacancies. ${ }^{37,38}$ Evidently, the initial state of $\mathrm{PdSn} / \mathrm{SiO}_{2}-\mathrm{C}$ favors production of 7-tridecanone (Fig. 6b) which decreases at later times on stream.

\subsubsection{Stability of PdSn catalysts}

The $\mathrm{SnO}_{x}$ species surrounding $\mathrm{Pd}$ sites in both physically-mixed and chemically-mixed $\mathrm{PdSn} / \mathrm{SiO}_{2}$ catalysts appear to promote the stability of the catalyst. Prior work demonstrated $\mathrm{SnO}_{\mathrm{x}}$ can supply oxygen-containing species that oxidatively remove $\mathrm{CH}_{3} \mathrm{CO}$ and $\mathrm{CO}$ adsorbed on adjacent noble metal

sites. ${ }^{40,41}$ In addition, $\mathrm{Pd}$-promoted $\mathrm{SnO}_{x} / \mathrm{SiO}_{2}$ has been reported to exhibit higher rates of $\mathrm{CO}$ oxidation compared to unpromoted $\mathrm{SnO}_{x} / \mathrm{SiO}_{2} \cdot{ }^{17}$ Thus, removal of product $\mathrm{CO}$ and unreacted heptanoic acid might be facilitated by the presence of Sn. Although an alloy phase was detected in the chemically mixed $\mathrm{PdSn} / \mathrm{SiO}_{2}-\mathrm{C}$, we suspect it resides in the few large bimetallic particles that would likely be irrelevant in the reaction.

\section{Conclusion}

The reactivity of silica-supported Pd, Sn, and PdSn bimetallic catalysts was evaluated in the conversion of heptanoic acid. Whereas monometallic Pd converted heptanoic acid primarily through 
decarbonylation, addition of $\mathrm{Sn}$ altered the reaction network to include dehydration and decarboxylative ketonization. In addition to altering the product distribution, addition of $\mathrm{Sn}$ to $\mathrm{Pd}$ improved the stability of the catalyst. Physically-mixed $\mathrm{PdSn} / \mathrm{SiO}_{2}-\mathrm{P}$ and chemically-mixed $\mathrm{PdSn} / \mathrm{SiO}_{2}-\mathrm{C}$ catalysts exhibited similar rates and selectivites after long times on stream, suggesting the final state of the catalyst is similar in both cases. Characterization of a used catalyst revealed a physical migration of Sn to Pd during reaction over the physical mixture. Analysis of Sn K-edge XANES suggests that the chemical state of $\mathrm{Sn}$ on the PdSn catalysts is a $\mathrm{SnO}_{x}$ species that forms under reaction conditions.

\section{Acknowledgements}

This material was based upon the work supported by the National Science Foundation under award number EEC-0813570. The XANES studies were funded by the Korea Institute of Energy Technology Evaluation and Planning (KETEP-20154030200830). The authors would like to acknowledge Dr. Helge Heinrich in the Department of Materials Science and Engineering at the University of Virginia as well as Ki-Duk Kim at Dankook University, South Korea. Helpful discussions with Dr. Derek Falcone, Zachary Young, and James Kammert are also acknowledged.

\section{References}

1. W. Keim, Pet. Chem., 2010, 50, 298-304. 
2. D. M. Alonso, S. G. Wettstein, and J. A. Dumesic, Chem. Soc. Rev., 2012, 41, 8075-98.

3. J. Swinnen and E. Tollens, Bioresour. Technol., 1991, 36, 277-291.

4. M. Snåre, I. Kubičková, P. Mäki-Arvela, K. Eränen, and D. Y. Murzin, Ind. Eng. Chem. Res., 2006, 5708-5715.

5. M. Snåre, I. Kubičková, P. Mäki-Arvela, D. Chichova, K. Eränen, and D. Y. Murzin, Fuel, 2008, 87, 933-945.

6. J. G. Immer, M. J. Kelly, and H. H. Lamb, Appl. Catal. A Gen., 2010, 375, 134-139.

7. R. Pestman, A. van Duijne, J. A. Z. Pieterse, and V. Ponec, J. Mol. Catal. A Chem., 1995, 1169.

8. S. Lestari, P. Mäki-Arvela, K. Eränen, J. Beltramini, G. Q. Max Lu, and D. Y. Murzin, Catal. Letters, 2009, 134, 250-257.

9. P. Mäki-Arvela, M. Snåre, K. Eränen, J. Myllyoja, and D. Y. Murzin, Fuel, 2008, 87, 3543-3549.

10. E. W. Ping, J. Pierson, R. Wallace, J. T. Miller, T. F. Fuller, and C. W. Jones, Appl. Catal. A Gen., 2011, 396, 85-90.

11. K. Sun, A. R. Wilson, S. T. Thompson, and H. H. Lamb, ACS Catal., 2015, 5, 1939-1948.

12. J. A. Lopez-Ruiz and R. J. Davis, Green Chem., 2014, 16, 683.

13. J. A. Lopez-Ruiz, H. N. Pham, A. K. Datye, and R. J. Davis, Appl. Catal. A Gen., 2015, 1-13.

14. F. E. López-Suárez, C. T. Carvalho-Filho, A. Bueno-López, J. Arboleda, A. Echavarría, K. I. B. Eguiluz, and G. R. Salazar-Banda, Int. J. Hydrogen Energy, 2015, 40, 12674-12686.

15. D. Rodríguez, J. Sánchez, and G. Arteaga, J. Mol. Catal. A Chem., 2005, 228, 309-317.

16. S. Nishiyama, T. Kubota, and K. Kimura, J. Mol. Catal. A, 1997, 1169.

17. G. C. Bond, R. Molloy, and M. J. Fuller, J. Chem. Soc. Chem. Commun., 1975, 2-3.

18. T. E. Tshabalala, N. J. Coville, and M. S. Scurrell, Appl. Catal. A Gen., 2014, 485, 238-244.

19. G. W. Huber, J. W. Shabaker, and J. A. Dumesic, Science, 2003, 300, 2075-7.

20. T. M. Yeh, R. L. Hockstad, S. Linic, and P. E. Savage, Fuel, 2015, 156, 219-224.

21. R. Alcala, J. W. Shabaker, G. W. Huber, M. A. Sanchez-Castillo, and J. A. Dumesic, J. Phys. Chem. B, 2005, 109, 2074-2085.

22. R. Burch and L. C. Garla, J. Catal., 1981, 71, 360-372. 
23. M. Chiappero, P. T. M. Do, S. Crossley, L. L. Lobban, and D. E. Resasco, Fuel, 2011, 90, 1155-1165.

24. Y. M. Lam and M. Boudart, J. Catal., 1977, 50, 530-540.

25. H. Nakatsuji, M. Hada, and T. Yonezawa, J. Am. Chem. Soc., 1987, 19, 1902-1912.

26. H. N. Pham, J. J. H. B. Sattler, B. M. Weckhuysen, and A. K. Datye, ACS Catal., 2016, 6, 2257-2264.

27. R. J. Davis and M. Boudart, J. Phys. Chem., 1994, 98, 5471-5477.

28. H. Cho and J. R. Regalbuto, Catal. Today, 2015, 246, 143-153.

29. S. Lambert, N. Job, L. D'souza, M. F. R. Pereira, R. Pirard, B. Heinrichs, J. Figueiredo, J. Pirard, and J. Regalbuto, J. Catal., 2009, 261, 23-33.

30. L. Protesescu, A. J. Rossini, D. Kriegner, M. Valla, A. de Kergommeaux, M. Walter, K. V Kravchyk, M. Nachtegaal, J. Stangl, B. Malaman, P. Reiss, A. Lesage, L. Emsley, C. Copéret, and M. V Kovalenko, ACS Nano, 2014, 8, 2639-2648.

31. R. Gavagnin, L. Biasetto, F. Pinna, and G. Strukul, Appl. Catal. B Environ., 2002, 38, 91-99.

32. E. Esmaeili, A. M. Rashidi, A. A. Khodadadi, Y. Mortazavi, and M. Rashidzadeh, Fuel Process. Technol., 2014, 120, 113-122.

33. Y. K. Lugo-José, J. R. Monnier, and C. T. Williams, Appl. Catal. A Gen., 2014, 469, 410-418.

34. Y. K. Lugo-José, J. R. Monnier, A. Heyden, and C. T. Williams, Catal. Sci. Technol., 2014, 4, 39093916.

35. J. A. Andor, O. Berkesi, I. Dreveni, and E. Varga, Lubr. Sci., 1999, 11-2.

36. M. W. de Lange, J. G. van Ommen, and L. Lefferts, 2001, 220, 41-49.

37. T. Yokoyama and N. Yamagata, Appl. Catal. A Gen., 2001, 221, 227-239.

38. R. Pestman, R. M. Koster, J. A. Z. Pieterse, and V. Ponec, J. Catal., 1997, 168, 255-264.

39. J. Pritchard, G. A. Filonenko, R. van Putten, E. J. M. Hensen, and E. A. Pidko, Chem. Soc. Rev., 2015, 44, 3808-3833.

40. S. C. Zignani, E. R. Gonzalez, V. Baglio, S. Siracusano, and A. S. Aricò, Int. J. Electrochem. Sci., 2012, 7, 3155-3166.

41. H. Lu, Y. Fan, P. Huang, and D. Xu, J. Power Sources, 2012, 215, 48-52. 


\section{List of Tables}

Table 1: Physical properties of the Pd, Sn, and PdSn catalysts

\begin{tabular}{|c|c|c|c|c|c|c|}
\hline \multirow{2}{*}{ Catalyst } & \multirow{2}{*}{$\begin{array}{l}\text { Hydrogen } \\
\text { chemisorption } \\
\text { (mmol } \mathrm{H}_{2} / \mathrm{g} \text { of } \\
\text { catalyst) }\end{array}$} & \multirow{2}{*}{$\mathrm{H} / \mathrm{Pd}$ ratio } & \multirow{2}{*}{$\begin{array}{l}\text { Particle } \\
\text { diameter }^{a} \\
(\mathrm{~nm})\end{array}$} & \multirow{2}{*}{$\begin{array}{l}\text { Surface- } \\
\text { weighted } \\
\text { avg. } \\
\text { diameter } \\
\text { (nm) }\end{array}$} & \multicolumn{2}{|c|}{$\begin{array}{l}\text { Nominal meta } \\
\text { loading (wt \%) }\end{array}$} \\
\hline & & & & & $\mathbf{P d}$ & Sn \\
\hline $\mathrm{Pd} / \mathrm{SiO}_{2}-\mathrm{L}$ & 0.076 & 0.32 & 3.1 & $2.4 \pm 0.5$ & 5 & - \\
\hline $\mathrm{Pd} / \mathrm{SiO}_{2}-\mathrm{H}$ & 0.19 & 0.80 & 1.3 & $1.1 \pm 0.4$ & 5 & - \\
\hline $\mathrm{Sn} / \mathrm{SiO}_{2}$ & 0 & - & - & - & - & 5.6 \\
\hline $\mathrm{PdSn} / \mathrm{SiO}_{2}-\mathrm{C}$ & 0.0072 & 0.061 & - & - & 2.5 & 2.8 \\
\hline $\mathrm{PdSn} / \mathrm{SiO}_{2}-\mathrm{P}$ & 0.059 & 0.51 & - & & 2.5 & 2.8 \\
\hline
\end{tabular}

${ }^{\mathrm{a}}$ Result estimated from $1 /(\mathrm{H} / \mathrm{Pd})$.

${ }^{\mathrm{b}}$ Result calculated from $\sum d^{3} / \sum d^{2}$ where diameter $(\mathrm{d})$ is measured using STEM images.

Table 2: The \%CO during heptanoic acid conversion at $573 \mathrm{~K}$

\begin{tabular}{lcc}
\hline & & \%CO \\
\cline { 2 - 3 } Catalyst & TOS $=\mathbf{0 . 5 0 \mathbf { h } ^ { \mathrm { a } }}$ & TOS $=\mathbf{1 0 . 7 5 \mathbf { h } ^ { \mathrm { a } }}$ \\
\hline $\mathrm{Pd} / \mathrm{SiO}_{2}-\mathrm{L}$ & 68 & $88^{\mathrm{b}}$ \\
$\mathrm{Pd} / \mathrm{SiO}_{2}-\mathrm{H}$ & 71 & $88^{\mathrm{c}}$ \\
$\mathrm{PdSn} / \mathrm{SiO}_{2}-\mathrm{C}$ & 8 & 50 \\
$\mathrm{PdSn} / \mathrm{SiO}_{2}-\mathrm{P}$ & 60 & 39 \\
\hline
\end{tabular}

${ }^{\mathrm{a}} \mathrm{TOS}$ represents time on stream

${ }^{\mathrm{b}}$ Result taken at $10 \mathrm{~h}$ time on stream.

${ }^{\mathrm{c}}$ Result taken at $11 \mathrm{~h}$ time on stream.

Table 3: The \%CO during heptanoic acid conversion at $573 \mathrm{~K}$ over two separated catalyst beds

\begin{tabular}{|c|c|c|}
\hline \multirow{2}{*}{$\begin{array}{c}\text { Catalyst } \\
\text { configuration }\end{array}$} & \multicolumn{2}{|c|}{$\%$ CO } \\
\hline & TOS $=0.50 h^{a}$ & TOS $=10.75 h^{a}$ \\
\hline $\mathrm{Sn} / \mathrm{Pd}$ & 64 & 54 \\
\hline $\mathrm{Pd} / \mathrm{Sn}$ & 76 & 94 \\
\hline
\end{tabular}

\footnotetext{
${ }^{\mathrm{a}} \mathrm{TOS}$ represents time on stream
} 


\section{List Figures}

A) Decarbonylation

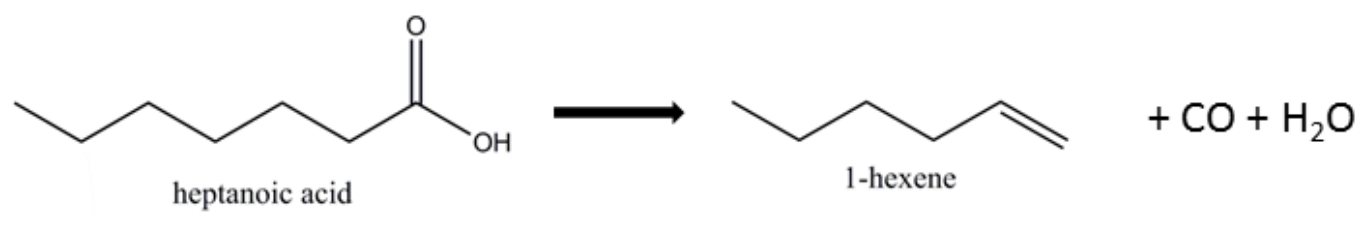

B) Decarboxylation

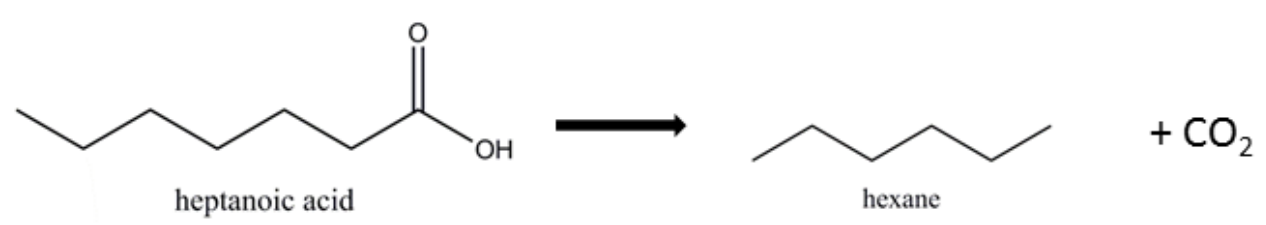

C) Decarboxylative ketonization<smiles>CCCCCCC(=O)OCCCCCCCC(=O)CCCCCCC(=O)O</smiles>

\section{D) Dehydration}

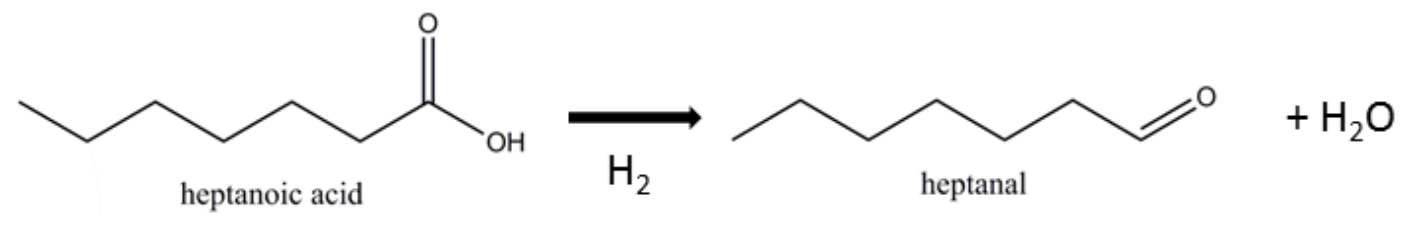

Scheme 1: Deoxygenation of heptanoic acid via A) decarbonylation, B) decarboxylation, C) decarboxylative ketonization, and $\mathrm{D}$ ) dehydration. 

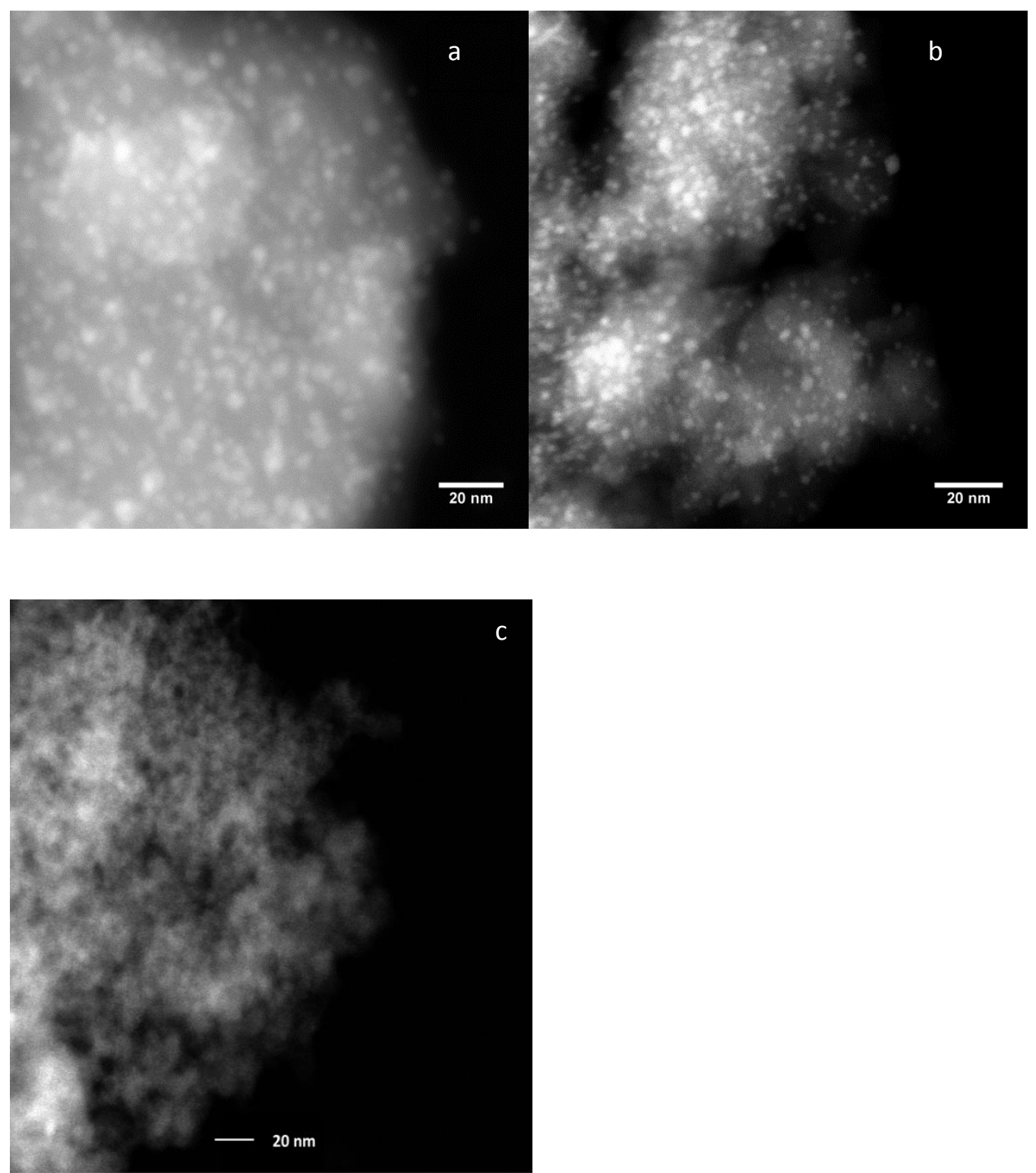

Figure 1: Dark field STEM images of fresh a) $\mathrm{Pd} / \mathrm{SiO}_{2}-\mathrm{L}$, b) $\mathrm{Pd} / \mathrm{SiO}_{2}-\mathrm{H}$, and c) $\mathrm{Sn} / \mathrm{SiO}_{2}$ 


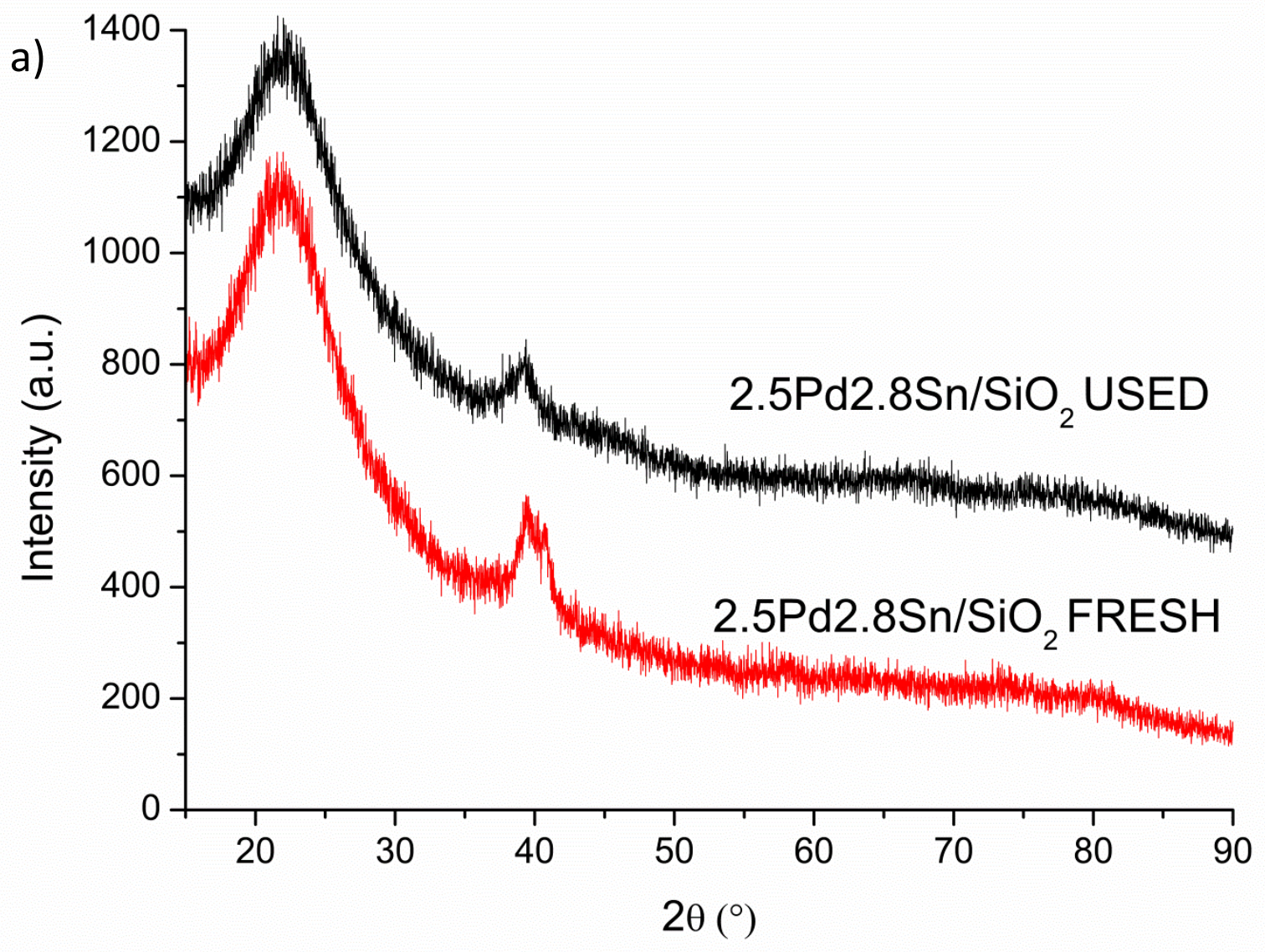




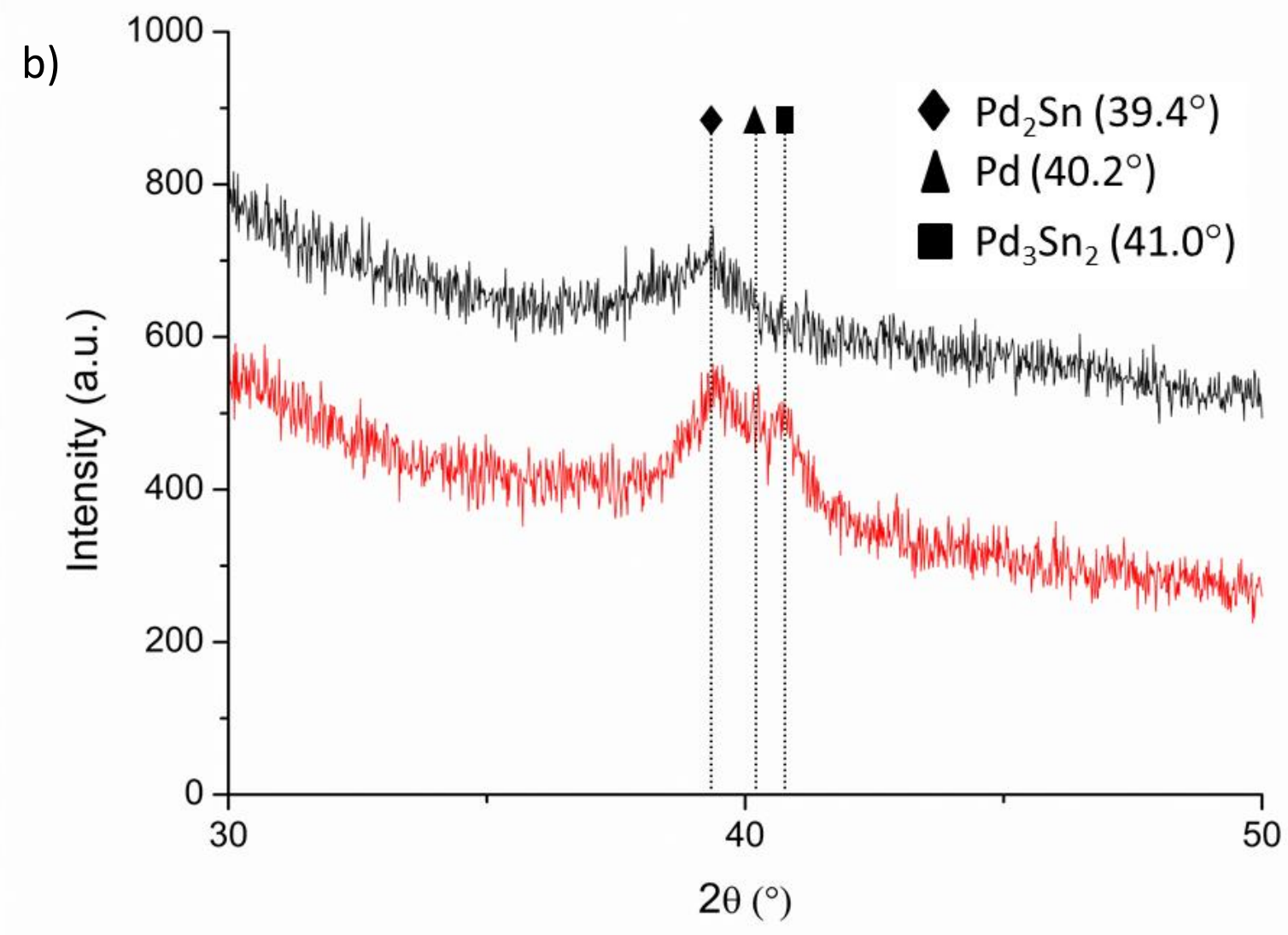

Figure 2: XRD pattern for fresh and used $\mathrm{PdSn} / \mathrm{SiO}_{2}-\mathrm{C}$ from a) $15^{\circ}-90^{\circ}$ and b) zoomed in to $30^{\circ}-50^{\circ}$. Used catalyst was tested for heptanoic acid conversion at $573 \mathrm{~K}$ and $0.1 \mathrm{MPa}$ for $10.75 \mathrm{~h}$.

a

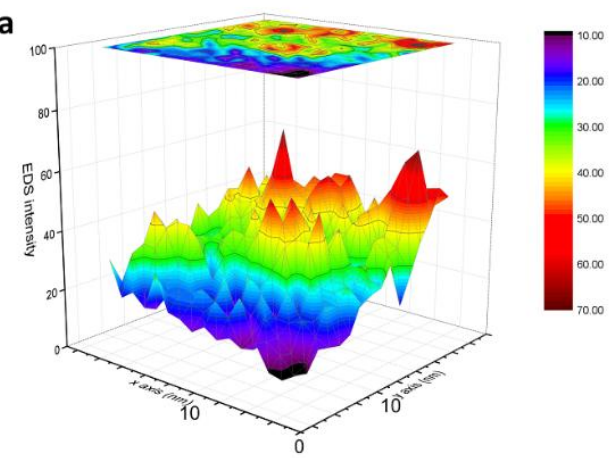

b

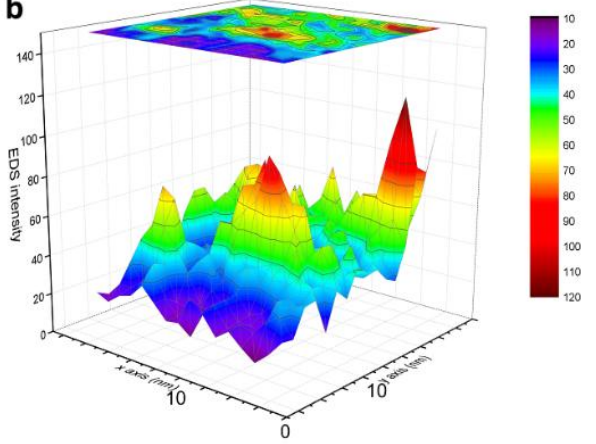

Figure 3: 3-D STEM-EDS map of used PdSn/SiO $2-\mathrm{P}$ : a) Pd-L map; b) Sn-L map. Used catalyst was tested for heptanoic acid conversion at $573 \mathrm{~K}$ and $0.1 \mathrm{MPa}$ for $10.75 \mathrm{~h}$. 
a

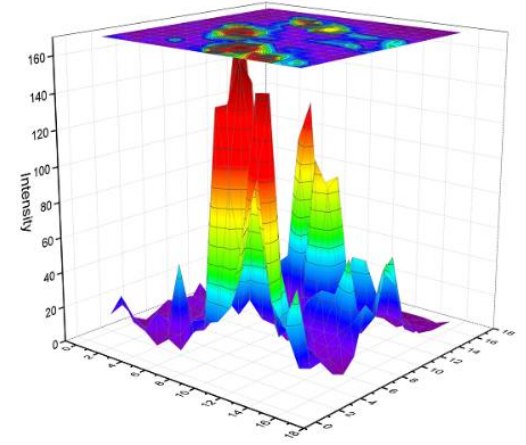

b

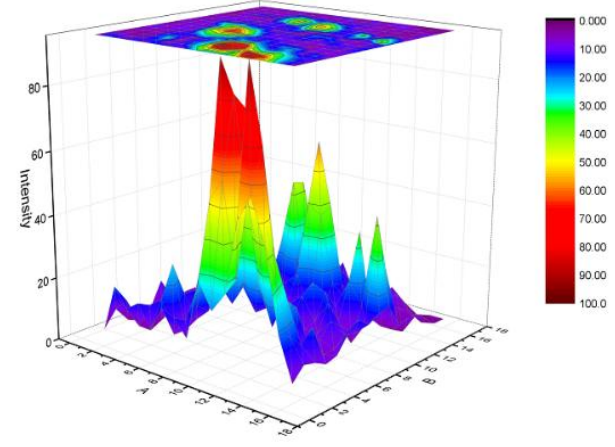

Figure 4: 3-D STEM-EDS map of used PdSn/SiO $2-\mathrm{C}$ : a) Pd-L map; b) Sn-L map. Used catalyst was tested for heptanoic acid conversion at $573 \mathrm{~K}$ and $0.1 \mathrm{MPa}$ for $10.75 \mathrm{~h}$.

a)

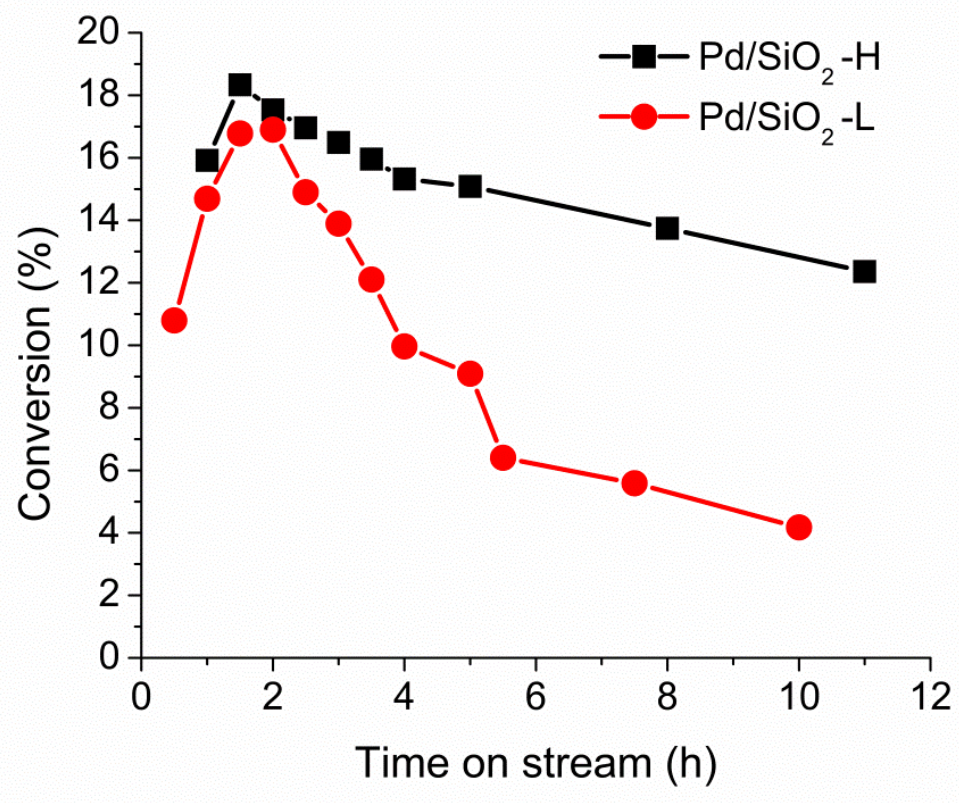


b)
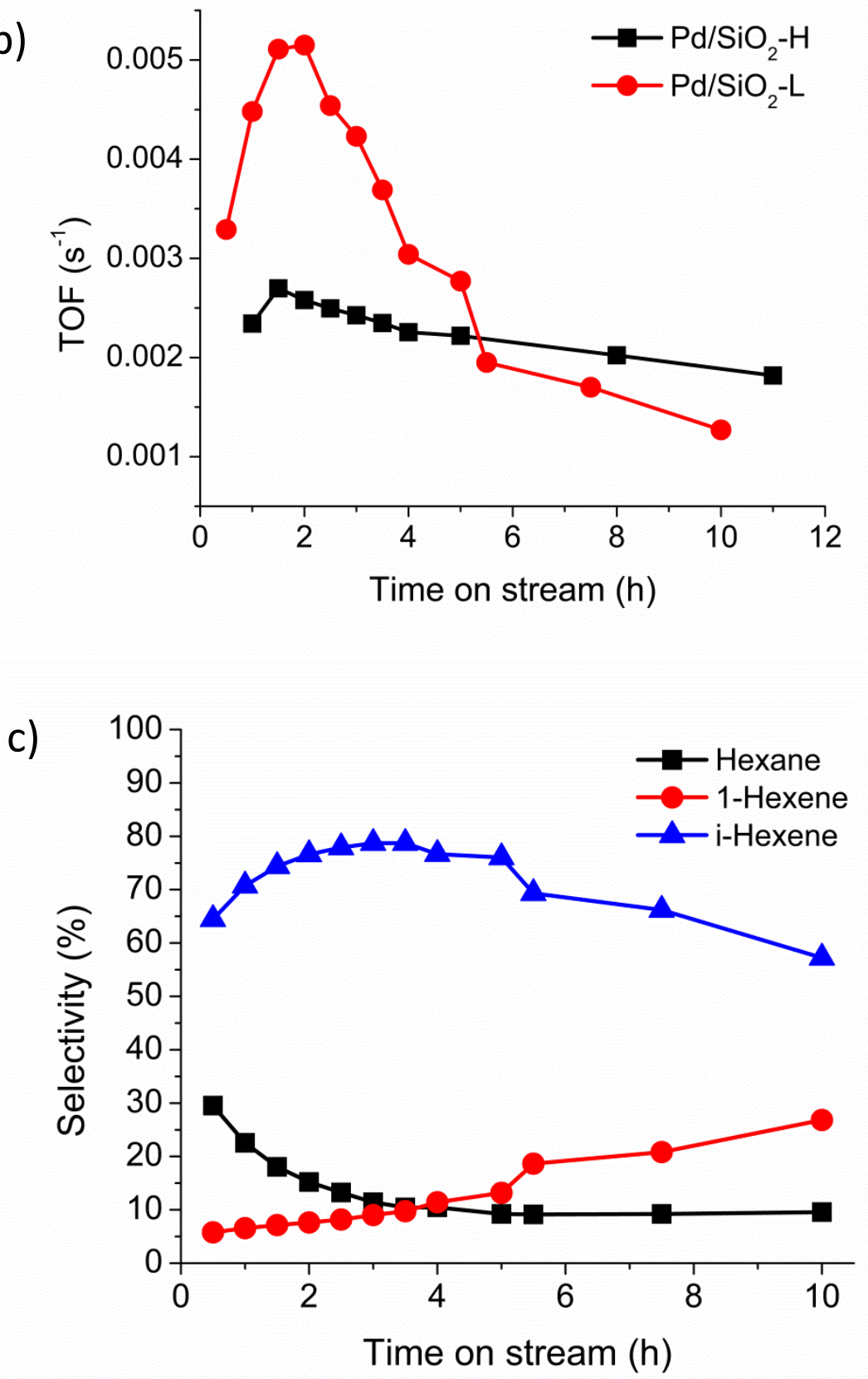


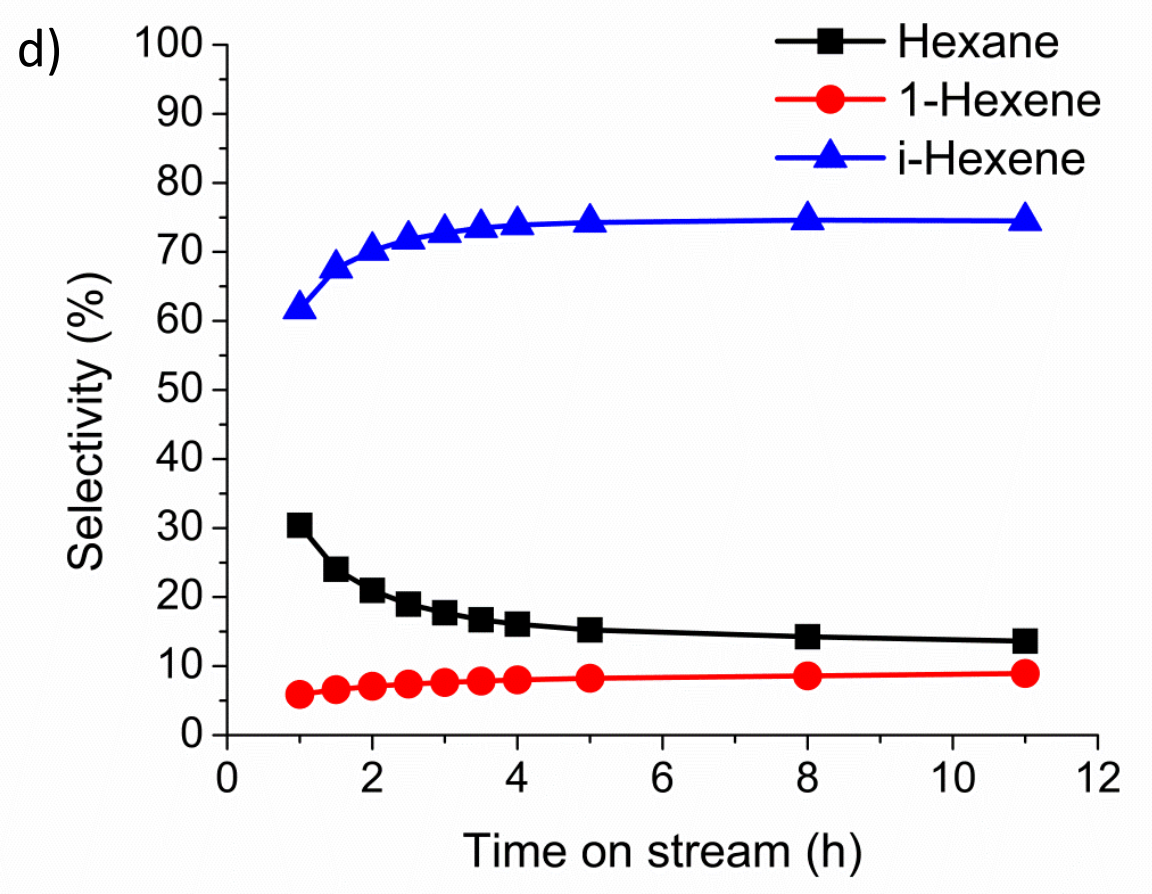

Figure 5: a) Conversion and b) TOF of heptanoic acid deoxygenation at $573 \mathrm{~K}$ and $0.1 \mathrm{MPa}$ over $\mathrm{Pd} / \mathrm{SiO}_{2}-\mathrm{L}$ and $\mathrm{Pd} / \mathrm{SiO}_{2}-\mathrm{H}$. Product selectivities are shown for c) $\mathrm{Pd} / \mathrm{SiO}_{2}-\mathrm{L}$ and d) $\mathrm{Pd} / \mathrm{SiO}_{2}-\mathrm{H}$. 

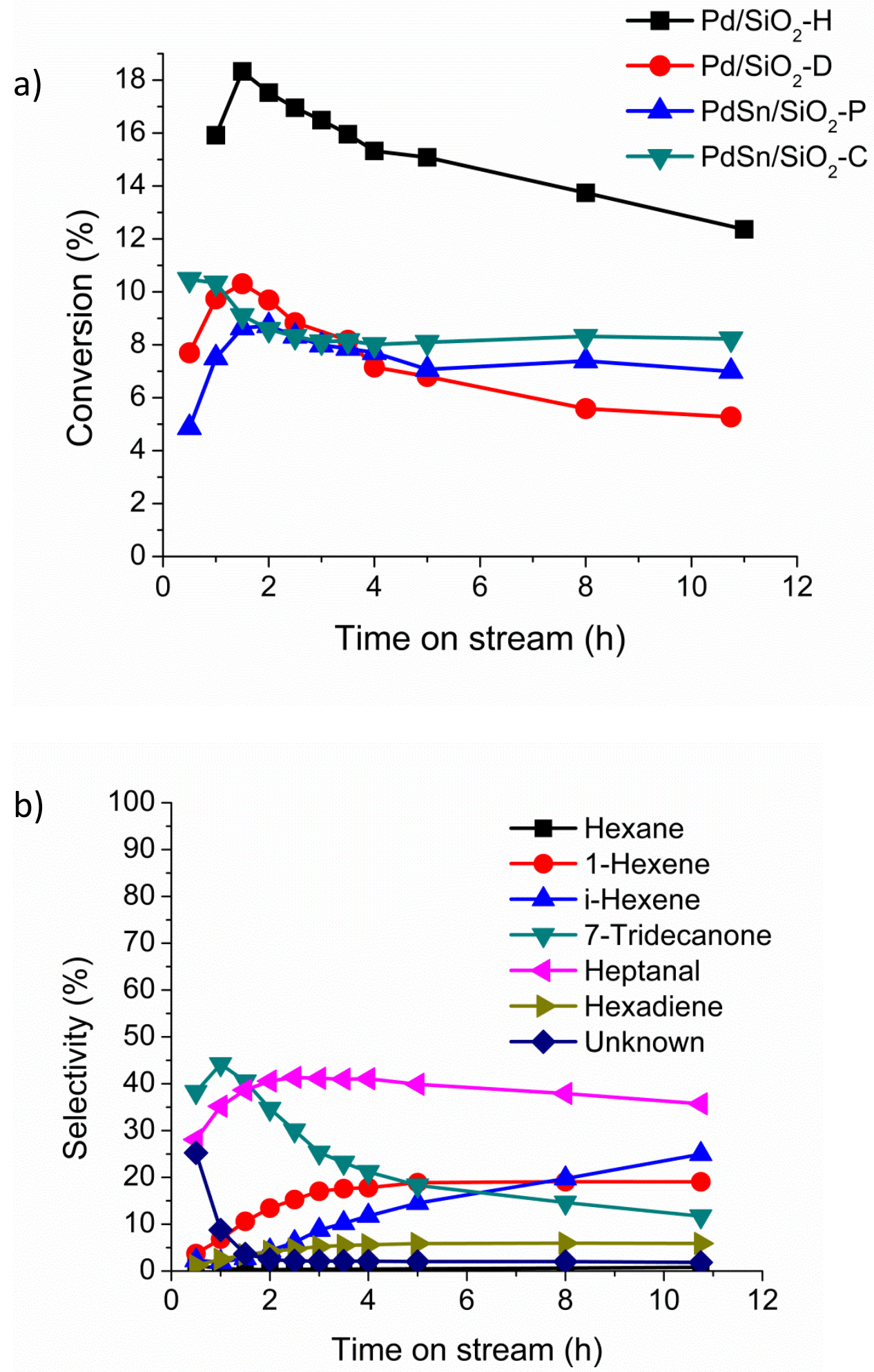
c)

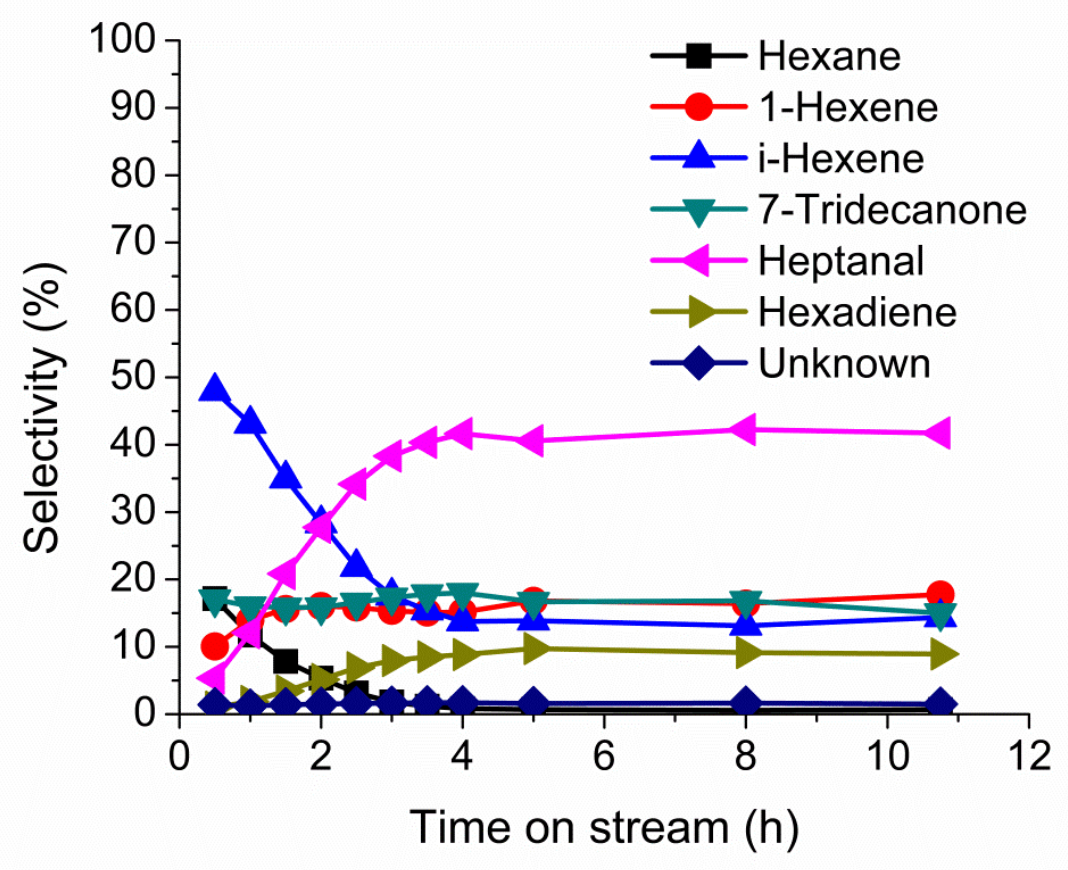

Figure 6: a) Conversion of heptanoic acid at $573 \mathrm{~K}$ and $0.1 \mathrm{MPa}$ over $\mathrm{Pd} / \mathrm{SiO}_{2}-\mathrm{H}, \mathrm{Pd} / \mathrm{SiO}_{2}-\mathrm{D}, \mathrm{PdSn} / \mathrm{SiO}_{2}-\mathrm{C}$, and $\mathrm{PdSn} / \mathrm{SiO}_{2}-\mathrm{P}$ and selectivity to deoxygenation products over b) $\mathrm{PdSn} / \mathrm{SiO}_{2}-\mathrm{C}$ and c) $\mathrm{PdSn} / \mathrm{SiO}_{2}-\mathrm{P}$. 
a)
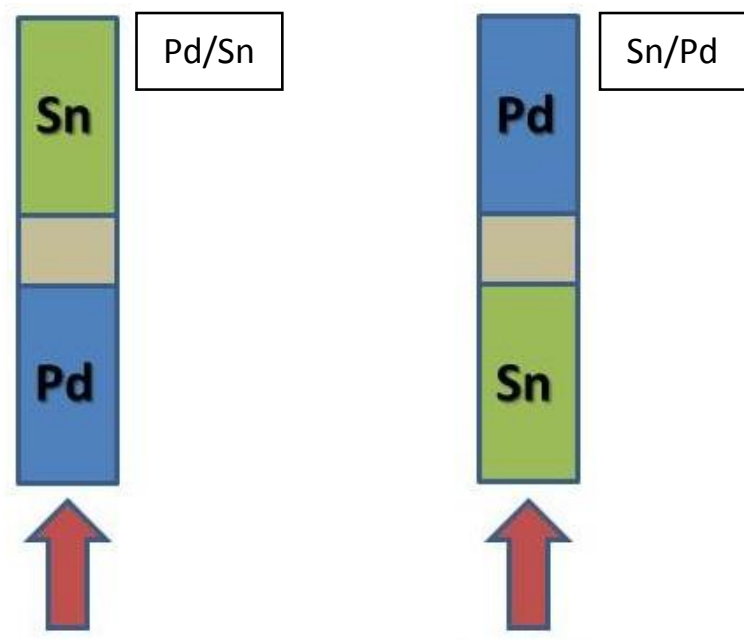

Upward

Flow

Upward

Flow

b)

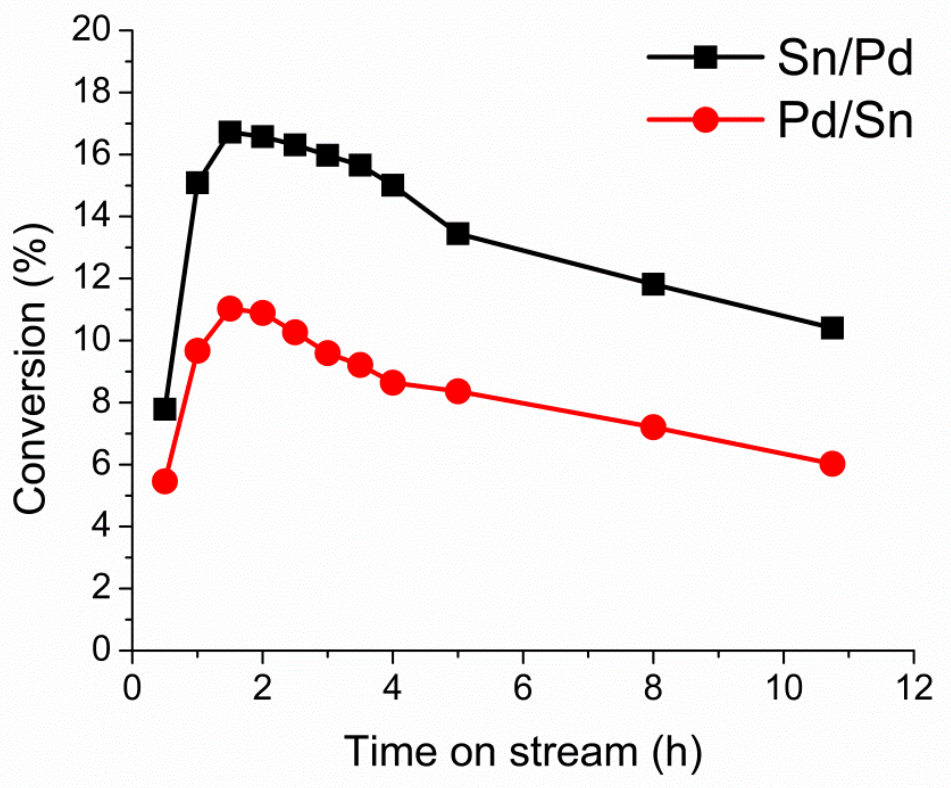



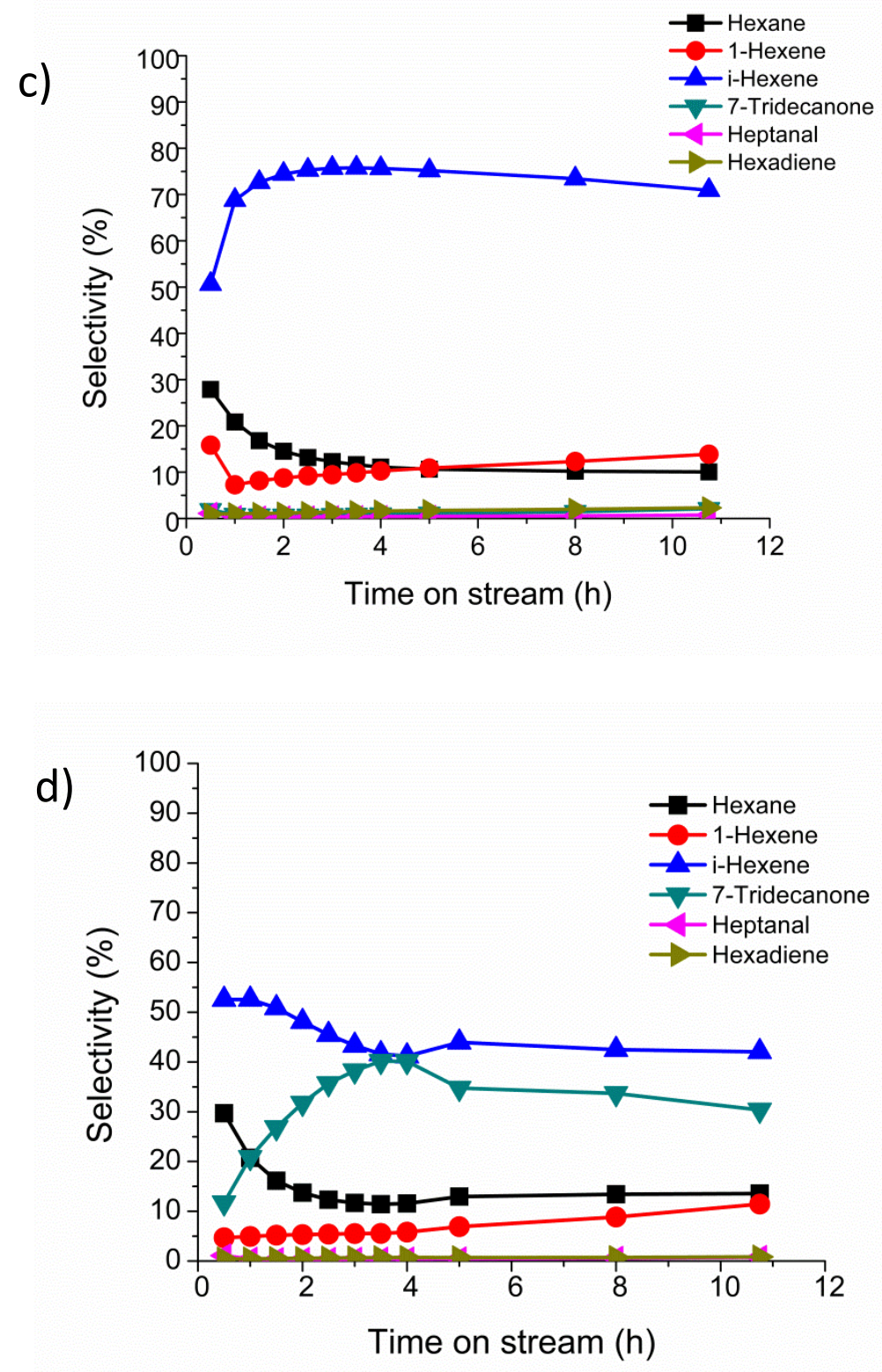

Figure 7: a) Configuration of two different catalyst beds in the reactor. Catalyst beds were separated by glass wool. Configurations are designated as $M_{1} / M_{2}$ where $M_{1}$ is the first catalyst to contact the reagent. b) Conversion of heptanoic acid at $573 \mathrm{~K}$ and $0.1 \mathrm{MPa}$ over separated beds of $\mathrm{Pd} / \mathrm{SiO}_{2}-\mathrm{H}$ and $\mathrm{Sn} / \mathrm{SiO}_{2}$. c) Product selectivity during reaction over Pd/Sn configuration. d) Product selectivity over Sn/Pd configuration. 
a)

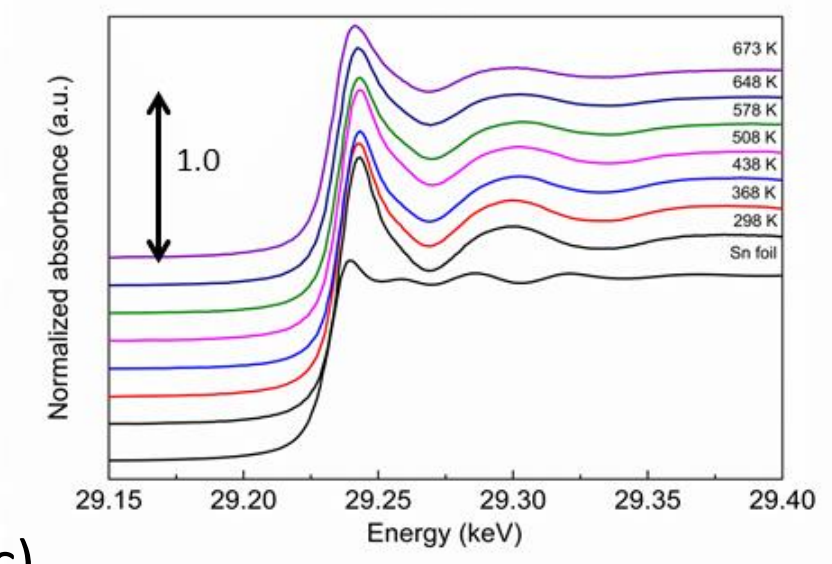

c)

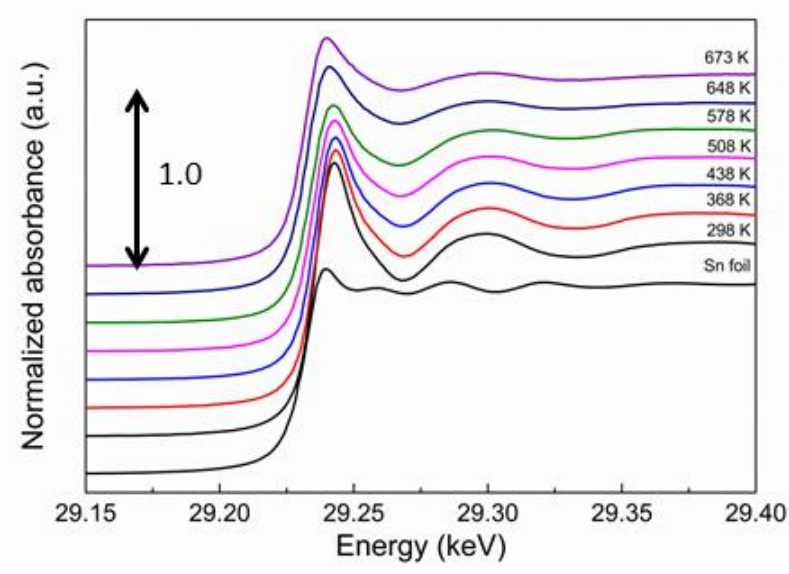

b)

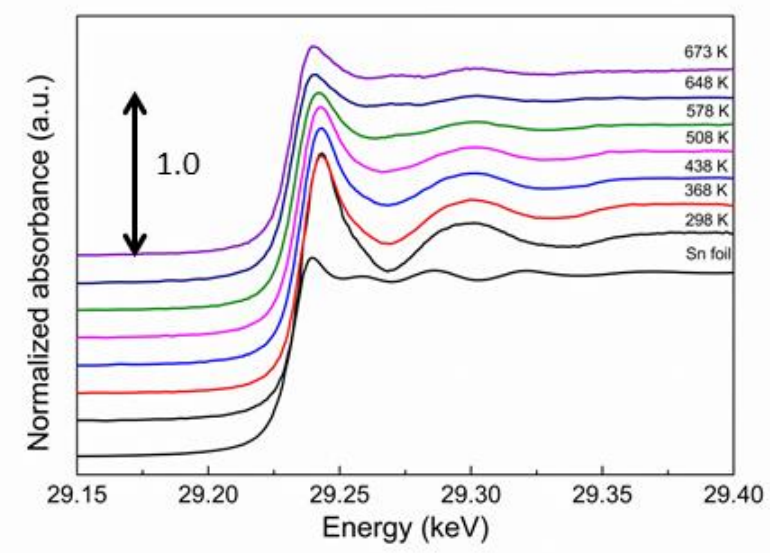

d)

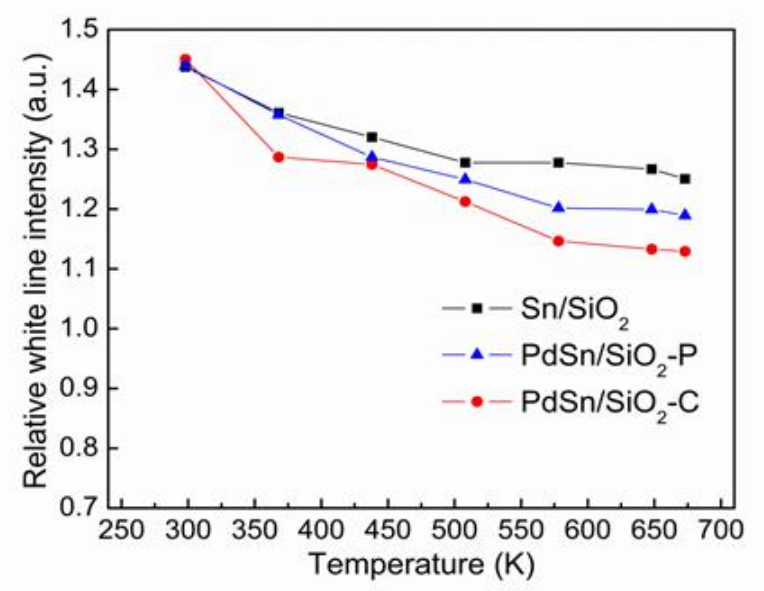

Figure 8: In situ Sn K-edge XANES spectra during temperature programmed reduction in $5 \% \mathrm{H}_{2}$ of a) $\mathrm{Sn} / \mathrm{SiO}_{2}$, b) $\mathrm{PdSn} / \mathrm{SiO}_{2}-\mathrm{C}$, c) PdSn/SiO $2-\mathrm{P}$, and d) comparison of white line intensities. Spectra are offset for clarity. 
a)

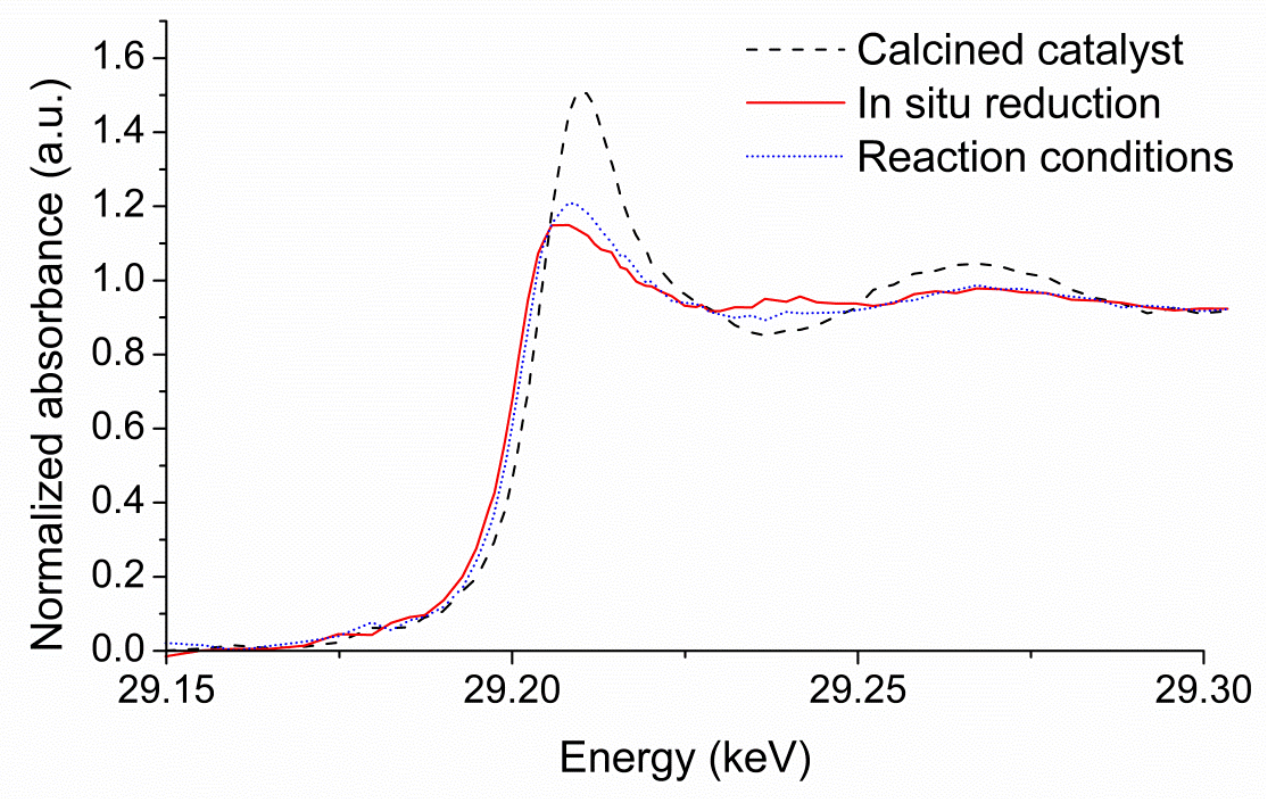

b)

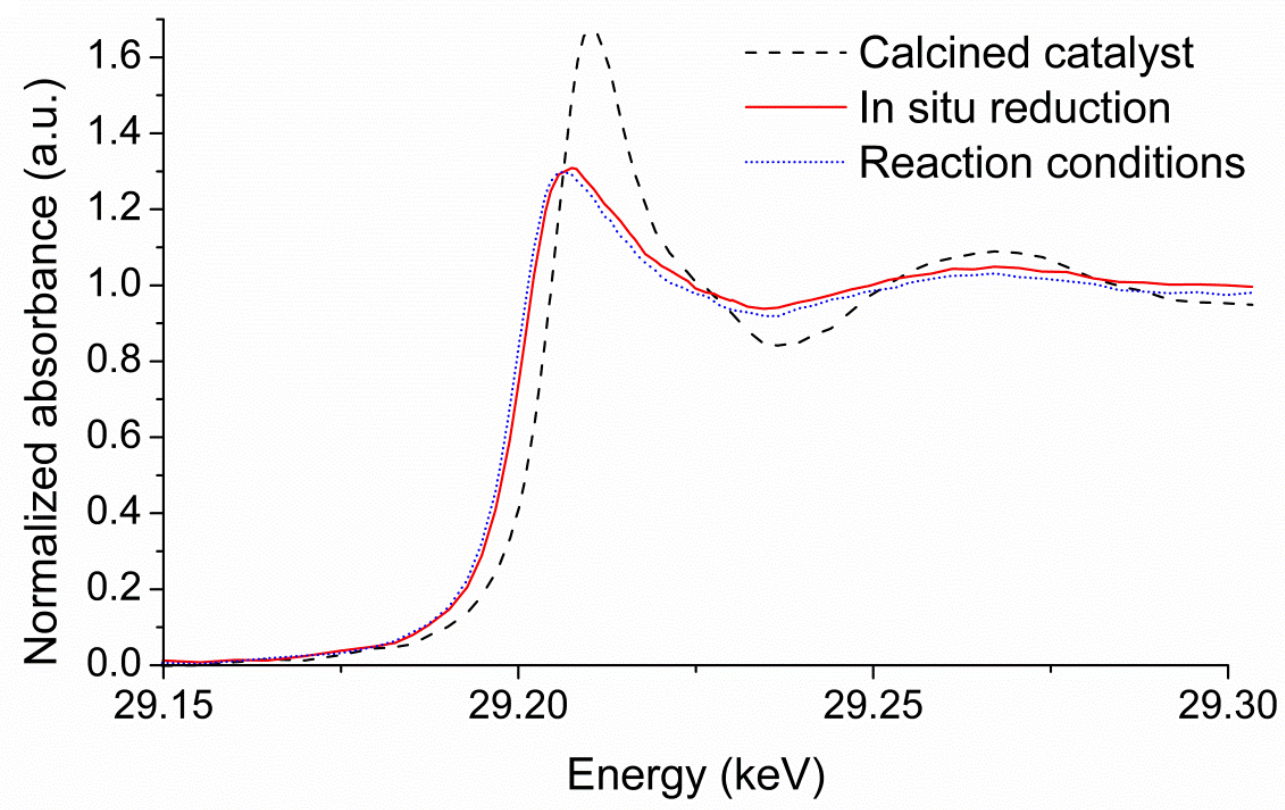

Figure 9: In situ Sn K-edge XANES of a) $\mathrm{PdSn} / \mathrm{SiO}_{2}-\mathrm{C}$ and b) $\mathrm{PdSn} / \mathrm{SiO}_{2}-\mathrm{P}$ during the conversion of butanoic acid. Spectra for "calcined catalyst" are associated with fresh, unreduced catalyst in flowing $\mathrm{N}_{2}$. Spectra for "in situ reduction" are associated with the catalyst after reduction in situ at $623 \mathrm{~K}$ for 30 min under $100 \mathrm{~cm}^{3} \mathrm{~min}^{-1} 5 \% \mathrm{H}_{2} / \mathrm{He}$. Spectra for "reaction conditions" are associated with the catalyst at $573 \mathrm{~K}$ after 150 min exposure to butanoic acid in $\mathrm{N}_{2}$. 
$\mathrm{Pd} / \mathrm{SiO}_{2}$

$\underbrace{\mathrm{PdSn} / \mathrm{SiO}_{2}}_{573 \mathrm{~K}, 0.1 \mathrm{MPa}}$

$\underbrace{\mathrm{OH}}_{573 \mathrm{~K}, 0.1 \mathrm{MPa}} \mathrm{PdSn} / \mathrm{SiO}_{2}$ $+\mathrm{H}_{2} \mathrm{O}$ 